\title{
rhIGF-1/rhIGFBP-3 in Preterm Infants: A Phase 2 Randomized Controlled Trial
}

\author{
David Ley, MD, PhD¹, Boubou Hallberg, MD, PhD², Ingrid Hansen-Pupp, MD, PhD¹, Carlo Dani, MD², \\ Luca A. Ramenghi, MD, $\mathrm{PhD}^{4}$, Neil Marlow, DM, FMedSci ${ }^{5}$, Kathryn Beardsall, MD ${ }^{6}$, Faizah Bhatti, $\mathrm{MD}^{7}$, David Dunger, $\mathrm{MD}^{6}$, \\ Jason D. Higginson, $\mathrm{MD}^{8}$, Ajit Mahaveer, MRCPCH${ }^{9}$, Olachi J. Mezu-Ndubuisi, MD, OD ${ }^{10}$, Peter Reynolds, MB.BS, PhD ${ }^{11}$, \\ Carmen Giannantonio, MD, $\mathrm{PhD}^{12}$, Mirjam van Weissenbruch, $\mathrm{MD}, \mathrm{PhD}^{13}$, Norman Barton, $\mathrm{MD}, \mathrm{PhD}^{14}$, \\ Adina Tocoian, MD, PhD ${ }^{15}$, Mohamed Hamdani, $\mathrm{MS}^{14}$, Emily Jochim, MBA ${ }^{14}$, Alexandra Mangili, MD, MPH ${ }^{15}$, \\ Jou-Ku Chung, $\mathrm{PhD}^{14}$, Mark A. Turner, MRCPCH, PhD ${ }^{16}$, Lois E. H. Smith, MD, PhD ${ }^{17}$, and Ann Hellström, MD, PhD ${ }^{18}$, and on \\ behalf of the study team*
}

Objective To investigate recombinant human insulin-like growth factor 1 complexed with its binding protein (rhlGF1/rhIGFBP-3) for the prevention of retinopathy of prematurity (ROP) and other complications of prematurity among extremely preterm infants.

Study design This phase 2 trial was conducted from September 2014 to March 2016. Infants born at a gestational age of $23^{0 / 7}$ weeks to $27^{6 / 7}$ weeks were randomly allocated to rhIGF-1/rhlGFBP-3 (250 $\mu \mathrm{g} / \mathrm{kg} / 24$ hours, continuous intravenous infusion from $<24$ hours of birth to postmenstrual age $29^{6 / 7}$ weeks) or standard neonatal care, with follow-up to a postmenstrual age of $40^{4 / 7}$ weeks. Target exposure was $\geq 70 \%$ IGF-1 measurements within 28$109 \mu \mathrm{g} / \mathrm{L}$ and $\geq 70 \%$ intended therapy duration. The primary endpoint was maximum severity of ROP. Secondary endpoints included time to discharge from neonatal care, bronchopulmonary dysplasia, intraventricular hemorrhage, and growth measures.

Results Overall, 61 infants were allocated to rhIGF-1/rhIGFBP-3, 60 to standard care (full analysis set); 24 of 61 treated infants achieved target exposure (evaluable set). rhIGF-1/rhIGFBP-3 did not decrease ROP severity or ROP occurrence. There was, however, a $53 \%$ decrease in severe bronchopulmonary dysplasia in the full analysis set $(21.3 \%$ treated vs $44.9 \%$ standard care), and an $89 \%$ decrease in the evaluable set $(4.8 \%$ vs $44.9 \%$; $P=.04$ and $P=.02$, respectively) for severity distribution between groups. There was also a nonsignificant trend toward decrease in grades 3-4 intraventricular hemorrhage in the full analysis set $(13.1 \% \mathrm{vs} 23.3 \%)$ and in the evaluable set (8.3\% vs $23.3 \%)$. Fatal serious adverse events were reported in $19.7 \%$ of treated infants (12/61) and $11.7 \%$ of control infants (7/60). No effect was observed on time to discharge from neonatal care/growth measures.

Conclusions rhIGF-1/rhIGFBP-3 did not affect development of ROP, but decreased the occurrence of severe bronchopulmonary dysplasia, with a nonsignificant decrease in grades 3-4

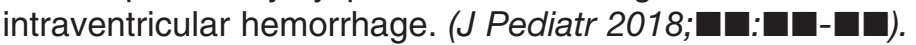

Trial registration ClinicalTrials.gov: NCT01096784.

nsulin-like growth factor-1 (IGF-1) is an important fetal growth regulator, with IGF-1 levels increasing with gestational age, particularly during the second and third trimesters of pregnancy. ${ }^{1,2}$ After preterm birth, serum IGF-1 levels decrease rapidly and remain low for the first weeks of life relative to corresponding fetal levels in utero. ${ }^{3,4}$

Longitudinal studies have reported an association between lower serum IGF-1 levels at birth in extremely preterm infants and an increased risk of retinopathy of prematurity (ROP), bronchopulmonary dysplasia (BPD), neurodevelopmental

\begin{tabular}{|llll|}
\hline AE & Adverse event & PMA & Postmenstrual age \\
BPD & Bronchopulmonary dysplasia & rh & Recombinant human \\
ES & Evaluable set & ROP & Retinopathy of prematurity \\
FAS & Full analysis set & rhIGF-1/ & rhlGF-1 complexed with its \\
IGF-1 & Insulin-like growth factor-1 & rhlGFBP-3 & binding protein rhIGFBP-3 \\
IVH & Intraventricular hemorrhage & SAE & Serious AE \\
NEC & Necrotizing enterocolitis & & \\
\hline
\end{tabular}

*List of additional members of the study team is available at www.jpeds.com (Appendix 1)

Detailed affiliations available at www.jpeds.com

Funded by Shire. Shire participated in the design of the study, the collection and analysis of data, and preparation of the clinical study report. D.L. and I.H-P. hold stock/ stock options in Premalux $A B$, and received consulting fees from Shire. B.H. received consulting fees from Premacure $\mathrm{AB}$ and Shire. L.R. received consulting fees and research support from Shire. N.M. received consulting fees from Shire, and partial funding from the Department of Health's National Institute for Health Department of Health's National Institute for Health
Research Biomedical Research Centre's funding scheme Research Biomedical Research Centre's funding scheme
at University College London Hospitals/University College London. K.B., F.B., J.H., O.M-N., M.vW., and L.S. received consulting fees from Shire. D.D. received consulting fees from Shire, and received consulting fees from Ipsen regarding other indications for IGF-1 therapies.

N.B., A.T., M.H., E.J., A.M., and J-K.C. are employees of N.B., A.T., M.H., E.J., A.M., and J-K.C. are employees of
and own stock/stock options in Shire. M.T.'s university received consulting fees from Shire. A.H. holds stock/ stock options in Premalux $A B$, and received consulting fees from Shire. C.D., A.M., P.R, and C.G. declare no conflicts of interest.

0022-3476/\$ - see front matter. ( 2018 The Author(s). Published by Elsevier Inc. This is an open access article under the CC BY-NC-ND license (http://creativecommons.org/licenses/by-nc-nd/4.0/).

https://doi.org10.1016/j.jpeds.2018.10.033 
impairment, and growth impairment. ${ }^{5-9}$ Preclinical models also support associations between IGF-1 and complications of prematurity. In mice, IGF-1 absence delays normal retinal vascular development, ${ }^{10}$ and recombinant human (rh)IGF-1 administration reduces risk of oxygen-induced retinopathy. ${ }^{11}$ Additionally, rhIGF-1 administration in a hyperoxia-induced model of BPD decreases signs of disease in newborn rats. ${ }^{12}$ Angiogenesis is an important process in both retinal and lung development, ${ }^{10,13}$ and it may represent a common underlying mechanism affected by low IGF-1 levels in ROP and BPD. ${ }^{10,14}$ In addition, IGF-1 is neuroprotective in rat pups affected by germinal matrix hemorrhage. ${ }^{15}$ Together, these data suggest that ROP, BPD, brain injury/neurodevelopmental impairment, and growth restriction could be ameliorated by supplementing postnatal serum IGF-1 to corresponding fetal levels in extremely preterm infants.

We are investigating the use of rhIGF- 1 complexed with its binding protein rhIGFBP-3 (rhIGF-1/rhIGFBP-3) to prevent complications of prematurity. Early clinical studies conducted between June 2010 and July 2013 demonstrated feasibility of rhIGF-1/rhIGFPB-3 infusion without safety concerns. ${ }^{16,17}$ In the current study, we hypothesized that rhIGF$1 /$ rhIGFBP- 3 administration by continuous intravenous infusion would decrease the severity of ROP and other complications of prematurity.

\section{Methods}

This phase 2, multicenter, randomized, standard of care concurrent control, assessor-masked study evaluated the efficacy and safety of rhIGF-1/rhIGFBP-3 in decreasing the severity of ROP and other complications of prematurity (ClinicalTrials.gov: NCT01096784). The trial was conducted at 20 clinical sites in Italy, the Netherlands, Poland, Sweden, the United Kingdom, and the US. Study drug was administered from within 24 hours after birth until postmenstrual age (PMA) $29^{6 / 7}$ weeks, with follow-up evaluations up to a PMA of $40^{4 / 7}$ weeks (Figure 1). All infants' parents/guardians provided written informed consent. The study was reviewed/approved by relevant institutional review boards/independent ethics committees. Additional details on safety monitoring and interim analyses are provided in the Methods section of Appendix 2 (available at www.jpeds.com). The study adhered to International Conference on Harmonization Good Clinical Practice guidelines and the tenets of the Declaration of Helsinki.

\section{Patient Population}

Infants with gestational age at birth of $23^{0 / 7}-27^{6 / 7}$ weeks were eligible for enrollment. Exclusion criteria included monozygotic twins, detectable gross malformation, known/suspected chromosomal abnormality, genetic disorder/syndrome, a persistent blood glucose level of $<2.5 \mathrm{mmol} / \mathrm{L}$ or $>10 \mathrm{mmol} / \mathrm{L}$ on the day of birth, anticipated need for administration of rh erythropoietin during treatment, a history of maternal diabetes requiring insulin, and clinically significant neurologic disease (germinal matrix hemorrhage allowed).

\section{Randomization and Masking}

Infants were allocated to rhIGF-1/rhIGFBP-3 or standard neonatal care (controls) in a 1:1. Dizygotic twins were randomized to the same study arm. Randomization was stratified by gestational age ( $<26, \geq 26$ weeks) centrally, using the permutedblock randomization approach. Investigators were not masked to treatment assignment, but certain assessments were masked. ROP stage was evaluated by 2 centralized independent pediatric ophthalmologists (and adjudicated by a third) and cranial ultrasound scans by a single central examiner.

\section{Treatment Regimen}

rhIGF-1/rhIGFBP-3 (mecasermin rinfabate, $50 \mu \mathrm{g} / \mathrm{mL}$ solution), a 1:1 molar ratio of the noncovalent complex of rhIGF-1 and rhIGFBP-3, was administered via continuous intravenous infusion through a central or peripheral line. Interruptions in the infusion of $\geq 1$ hour were recorded. Standard care was determined based on the individual preterm infant's condition following local protocols. The Methods section in Appendix 2 summarizes information on permitted and prohibited concomitant medications.

\section{Dosing and Target IGF-1 Levels}

rhIGF-1/rhIGFBP-3 dosing was standardized to $250 \mu \mathrm{g} / \mathrm{kg} /$ 24 hours with the intention of maintaining serum IGF-1 levels within $28-109 \mu \mathrm{g} / \mathrm{L}$, estimated as the normal physiologic intrauterine range based on prior literature. ${ }^{18-20}$ The dose was decreased to $125 \mu \mathrm{g} / \mathrm{kg} / 24$ hours if the infant's serum IGF-1 levels exceeded the upper bound for 2 consecutively scheduled samples (plus a confirmatory sample 12 hours after the previous 2 consecutive samples). The Methods section in Appendix 2 provides details on sampling intervals and methods for IGF-1 measurement.

\section{Outcomes}

The primary endpoint was maximum severity of ROP stage across all retinal examinations, based on retinal camera (RetCam, Clarity Medical Systems Inc, Pleasanton, California) images of the dilated fundus. ROP assessments were performed every 1-2 weeks between PMA 31 and 40 weeks. ROP was classified according to the International Classification. ${ }^{21}$ For treatment, the recommendations of the Early Treatment for Retinopathy of Prematurity Cooperative Group were followed. ${ }^{22}$ The International Classification is based on an ordinal scale with higher numbers indicating a more severe outcome: $0,1,2,3,3+, 4$, and 5 .

A prespecified key secondary endpoint was time between day of birth and day of discharge from neonatal care. Other secondary outcome measures included incidence of BPD and intraventricular hemorrhage (IVH) and assessment of growth (weight, length, and head circumference). BPD was assessed by need for oxygen use during the first 28 days after birth and by oxygen challenge testing at PMA of $36^{3 / 7}$ weeks. ${ }^{23,24}$ Definitions of mild, moderate, and severe BPD were based on the National Institute of Child Health and Human Development criteria for preterm infants born before 32 weeks of gestation. ${ }^{23}$ The presence of cerebral hemorrhage was assessed by cranial 


\section{A}

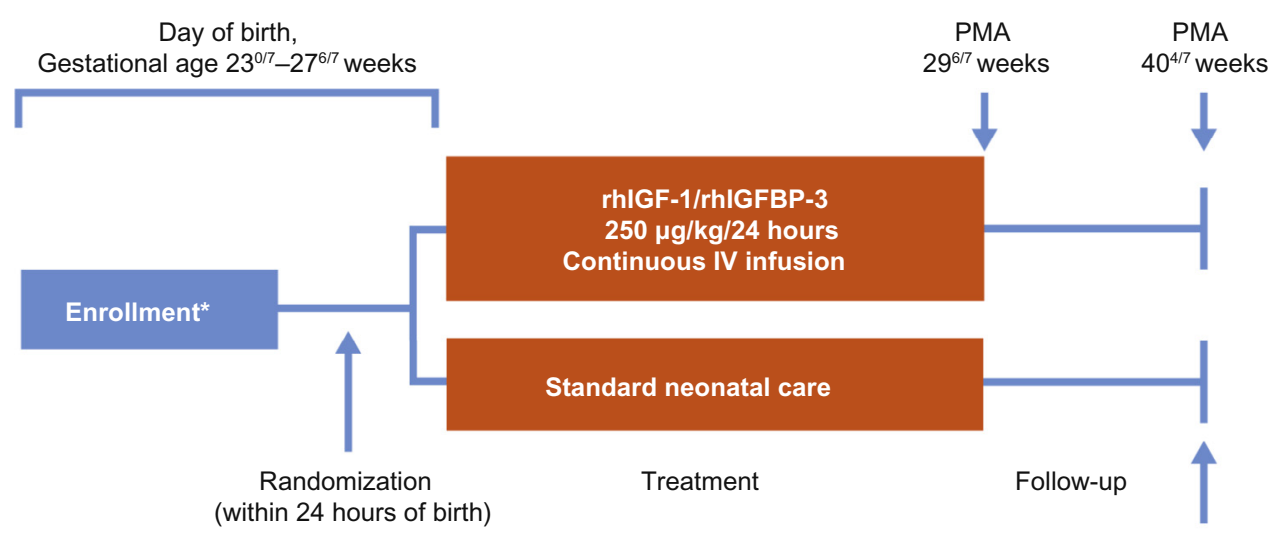

End of study

B

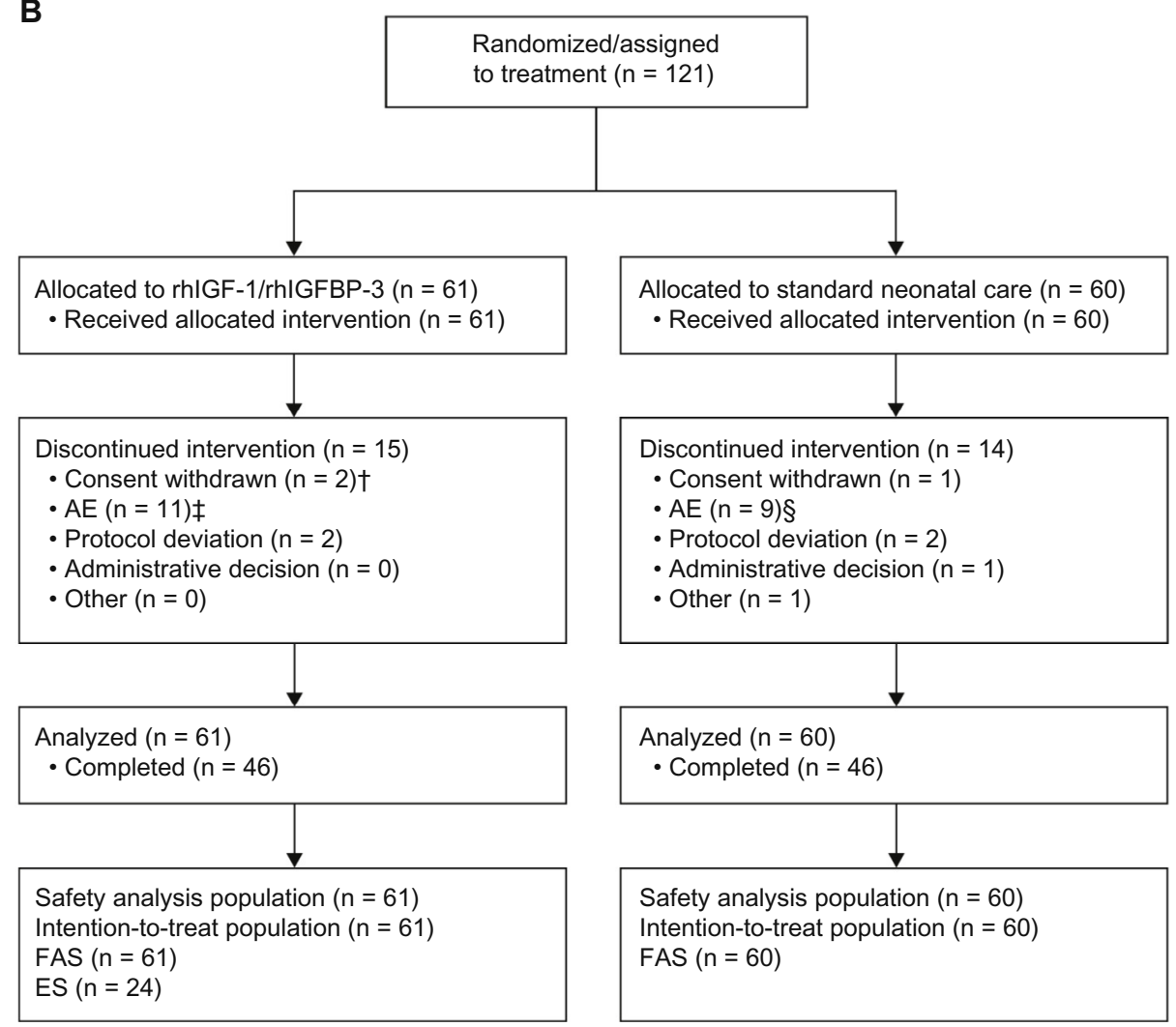

Figure 1. A, Study design and B, patient disposition. *Informed consent was obtained before birth or within 24 hours after birth. † One infant had an SAE with a fatal outcome, but the primary reason for discontinuation was withdrawal of consent. $\ddagger$ All infants discontinued owing to an SAE with fatal outcome. $\S$ Seven of 9 discontinuations were owing to SAEs with fatal outcome.

ultrasound scanning before study inclusion, at postnatal days $3,7,14$, and 21 ( \pm 1 day), and at PMA 40 weeks ( \pm 4 days), and graded between 0 and 4 using the Papile/Bowerman scoring method. ${ }^{25,26}$ Ultrasound images were graded by a single reader masked to study group. Brain volumetric measurements were performed on magnetic resonance images obtained at PMA 40 weeks and will be reported separately.

\section{Safety Assessments}

Adverse events (AEs) and serious AEs (SAEs) were recorded from receipt of informed consent until final study examination/ sampling at PMA 40 weeks. Investigator Verbatim Terms describing AEs were coded using the Medical Dictionary for Regulatory Activities (MedDRA; version 16.0) to MedDRA Preferred Terms (Table I [available at www.jpeds.com] for 
reported Verbatim Terms for commonly observed AEs). The Methods section in Appendix 2 describes other definitions and assessments of AEs.

\section{Statistical Analyses}

A sample size of 40 infants per treatment group (80 total) was estimated to provide $80 \%$ power (significance level, $5 \%$ ) to demonstrate a statistically significant difference in distribution of ROP maximum severity between groups (primary endpoint). The ROP outcome stages in the current study were classified as $0,1,2,3$, and $>3$, which is the expected possible range of ROP stages that would be encountered in the study, based on analysis of Swedish infants screened for ROP from 2004 to 2008. Based on Swedish registry data, ${ }^{27}$ the proportion of children with each ROP outcome for the control group is provided in Table II (available at www.jpeds.com). An estimated treatment effect among treated infants is also presented. The estimated treatment effect was calculated based on the following assumptions: For each outcome of the maximum severity of ROP stage, it is assumed that $25 \%$ of the children will not benefit from the treatment, $25 \%$ will have their maximum severity of ROP stage reduced by 1 level (eg, from 2 to 1 ), and $50 \%$ will have their maximum severity of ROP stage reduced 2 levels (eg, from $3+$ to 2 ). The null hypothesis tested whether the distribution of maximum severity of ROP stage across all retinal examinations was the same for both treatment groups. Assuming a 30\% nonevaluable/dropout rate, 120 infants (60 per group) were to be randomly assigned. The study was powered for the primary ROP endpoint only. A sample size of 80 evaluable infants was also estimated to provide adequate power for the key secondary endpoint (time to discharge from neonatal intensive care), but no power calculations were performed for BPD or IVH secondary endpoints. The Methods section in Appendix 2 provides additional details on the statistical evaluation of all endpoints.

The intention-to-treat population included all enrolled infants assigned a randomization number. The full analysis set (FAS) was defined as all randomized infants receiving study drug or standard care. For rhIGF-1/rhIGFBP-3-treated infants, the FAS was the same as the intention-to-treat population because all randomized infants started treatment. The evaluable set (ES) included treated infants in the FAS who had $\geq 70 \%$ of serum IGF- 1 levels within the target range (28-109 $\mu \mathrm{g} / \mathrm{L})$ and who received $\geq 70 \%$ of the intended duration of infusion of rhIGF-1/rhIGFBP-3 (overall infusion length excluding interruptions of $\geq 1$ hour). For the standard care group, the FAS was also considered to be the ES. The safety population included randomized infants receiving study drug or standard care for whom $\geq 1$ safety assessment was completed. The pharmacokinetic population included infants receiving study drug who had $\geq 1$ blood samples drawn after administration.

\section{Results}

The first infant was enrolled September 19, 2014, and the last infant completed March 30, 2016. Overall, 121 infants were enrolled, of whom 29 did not complete the study (19 of 29 owing

\begin{tabular}{|c|c|c|c|}
\hline Characteristics & $\begin{array}{c}\text { Standard } \\
\text { care } \\
(n=60)\end{array}$ & $\begin{array}{c}\text { rhIGF-1/ } \\
\text { rhIGFBP-3 } \\
\text { FAS } \\
(n=61)\end{array}$ & $\begin{array}{c}\text { rhIGF-1/ } \\
\text { rhIGFBP-3 } \\
\text { ES } \\
(n=24)\end{array}$ \\
\hline \multicolumn{4}{|l|}{ Sex, no. (\%) } \\
\hline Male & $39(65.0)$ & 39 (63.9) & $14(58.3)$ \\
\hline Female & $21(35.0)$ & $22(36.1)$ & $10(41.7)$ \\
\hline \multicolumn{4}{|l|}{ Gestational age group, no. (\%) } \\
\hline$<26$ wk & $32(53.3)$ & $35(57.4)$ & $10(41.7)$ \\
\hline$\geq 26$ wk & $28(46.7)$ & $26(42.6)$ & $14(58.3)$ \\
\hline \multicolumn{4}{|l|}{ Gestational age } \\
\hline Mean, wk & $25^{4 / 7}$ & $25^{4 / 7}$ & $25^{7 / 7}$ \\
\hline $\pm S D, d$ & \pm 10 & \pm 8 & \pm 9 \\
\hline SGA, no. $(\%)$ & $10(16.7)$ & $11(18.0)$ & NA \\
\hline \multicolumn{4}{|l|}{ Weight at birth } \\
\hline Mean, kg & 0.804 & 0.780 & 0.847 \\
\hline $\mathrm{SD}, \mathrm{kg}$ & 0.174 & 0.183 & 0.192 \\
\hline \multicolumn{4}{|l|}{ Race, no. (\%) } \\
\hline Asian & $5(8.3)$ & $4(6.6)$ & $1(4.2)$ \\
\hline Black or African American & $9(15.0)$ & $5(8.2)$ & $3(12.5)$ \\
\hline White & $42(70.0)$ & $49(80.3)$ & 19 (79.2) \\
\hline Other & $4(6.6)$ & $3(4.9)$ & $1(4.2)$ \\
\hline \multicolumn{4}{|l|}{ Mode of delivery, no. (\%) } \\
\hline Vaginal & $27(45.0)$ & $25(41.0)$ & $10(41.7)$ \\
\hline Cesarean & $33(55.0)$ & $36(59.0)$ & $14(58.3)$ \\
\hline Maternal infections, no. (\%) & $14(23.3)$ & $11(18.0)$ & $3(12.5)$ \\
\hline Clinical chorioamnionitis, no. (\%) & $6(10.0)$ & $10(16.4)$ & $2(8.3)$ \\
\hline Maternal antibiotics, no. (\%) & $38(63.3)$ & $32(52.5)$ & $12(50.0)$ \\
\hline Antenatal steroids, no. (\%) & $60(100.0)$ & $61(100.0)$ & $24(100.0)$ \\
\hline Fertility therapy, no. (\%) & $9(15.0)$ & $10(16.4)$ & $2(8.3)$ \\
\hline IVF & $7(11.7)$ & $10(16.4)$ & $2(8.3)$ \\
\hline Ovulation stimulation & $2(3.3)$ & 0 & 0 \\
\hline Preterm labor, no. (\%) & $53(88.3)$ & $50(82.0)$ & $19(79.2)$ \\
\hline $\begin{array}{l}\text { Preterm premature rupture } \\
\text { of membranes, no. (\%) }\end{array}$ & $20(33.3)$ & $18(29.5)$ & 8 (33.3) \\
\hline Preeclampsia, no. (\%) & $5(8.3)$ & $7(11.5)$ & $2(8.3)$ \\
\hline
\end{tabular}

$I V F$, in vitro fertilization; $N A$, not available; SGA, small for gestational age.

to death; Figure 1). Sixty-one infants received rhIGF-1/ rhIGFBP-3 and 60 standard of care. Thirty-five of 61 treated infants (57.4\%) and 32 of 60 control infants (53.3\%) were born before 26 weeks gestational age (Table III). Mean average daily dose of rhIGF-1/rhIGFBP-3 was $248.1 \mu \mathrm{g} / \mathrm{kg} / 24$ hours (range, $131.1-250.0 \mu \mathrm{g} / \mathrm{kg} / 24$ hours); the total duration of exposure was 23.8 days (range, 0.1-45.3 days); the ratio of duration of exposure to expected duration (birth to $29^{6 / 7}$ weeks PMA) was 0.86 (range, 0.0-1.0); and the number of infusion interruptions of $\geq 1$ hour was 4.0 per treated infant (range, $0-83$ per treated infant). Table IV (available at www.jpeds.com) provides details on exposure by gestational age strata. Among treated infants, 52 of 61 received $\geq 70 \%$ of the expected treatment duration and 28 of 61 had $\geq 70 \%$ of IGF- 1 levels within the target range. Overall target exposure (based on duration and IGF-1 level) was achieved for 24 of 61 treated infants (ES). The Results section in Appendix 2 and Figure 2 (available at www.jpeds.com) summarize information on attained serum IGF-1 levels.

\section{Primary Endpoint: ROP}

Considering the FAS, $25.5 \%$ of rhIGF-1/rhIGFBP-3-treated infants developed ROP stage $\geq 3$ vs $18.0 \%$ of controls; there 


\begin{tabular}{|c|c|c|c|}
\hline & \multirow{2}{*}{$\begin{array}{c}\text { Standard } \\
\text { care } \\
(n=60)\end{array}$} & \multicolumn{2}{|c|}{ rhIGF-1/rhIGFBP-3 } \\
\hline & & FAS $(n=61)$ & $E S(n=24)$ \\
\hline \multicolumn{4}{|l|}{ ROP } \\
\hline $\begin{array}{l}\text { Infants with ROP examination, no. } \\
\text { Infants with maximum severity } \\
\text { of ROP of stage, no. }(\%)\end{array}$ & 50 & 47 & 22 \\
\hline 0 & $24(48.0)$ & $14(29.8)$ & $8(36.4)$ \\
\hline 1 & $4(8.0)$ & $4(8.5)$ & $2(9.1)$ \\
\hline 2 & $13(26.0)$ & $17(36.2)$ & $8(36.4)$ \\
\hline 3 & $3(6.0)$ & $6(12.8)$ & $2(9.1)$ \\
\hline $3+$ & $6(12.0)$ & $6(12.8)$ & $2(9.1)$ \\
\hline 4 & 0 & 0 & 0 \\
\hline 5 & 0 & 0 & 0 \\
\hline$\geq 3$ & $9(18.0)$ & $12(25.5)$ & $4(18.2)$ \\
\hline Missing, no.* & 10 & 14 & 2 \\
\hline $\begin{array}{l}P \text { value }^{\dagger} \\
\text { BPD }\end{array}$ & & .06 & .24 \\
\hline $\begin{array}{l}\text { Infants with BPD assessment, no. } \\
\text { Severity of BPD, no. (\%) }\end{array}$ & 49 & 47 & 21 \\
\hline No BPD & $4(8.2)$ & $4(8.5)$ & $2(9.5)$ \\
\hline Mild & $16(32.7)$ & $23(48.9)$ & $13(61.9)$ \\
\hline Moderate & 5 (10.2) & 9 (19.1) & $5(23.8)$ \\
\hline Severe & $22(44.9)$ & $10(21.3)$ & $1(4.8)$ \\
\hline Unable to determine & $2(4.1)$ & $1(2.1)$ & 0 \\
\hline$P$ value $^{\dagger}$ & & $.04^{\ddagger}$ & $.02^{\ddagger}$ \\
\hline \multicolumn{4}{|l|}{ IVH } \\
\hline \multicolumn{4}{|l|}{ IVH grade, no. (\%) } \\
\hline $0-1$ & $42(70.0)$ & $49(80.3)$ & $20(83.3)$ \\
\hline 2 & $4(6.7)$ & $4(6.6)$ & $2(8.3)$ \\
\hline 3 & $9(15.0)$ & $6(9.8)$ & $2(8.3)$ \\
\hline 4 & $5(8.3)$ & $2(3.3)$ & 0 \\
\hline$P$ value $^{\dagger}$ & & .14 & .18 \\
\hline
\end{tabular}

${ }^{*}$ The majority (11/12 treated [FAS] and 5/7 control infants) of infants who died in this study had died before the first scheduled ROP assessment at week 31. Other reasons for not being evaluated included withdrawal of consent and difficulties in capturing quality RetCam images. tCochran-Mantel-Haenszel row mean score test.

ҒDifference in the distribution of BPD severity seen between the rhIGF-1/rhIGFBP-3 (FAS or ES) and standard care groups is statistically significant.

was no statistically significant difference between the 2 groups in distribution of maximum severity of $\operatorname{ROP}(P=.06$; Table $\mathrm{V})$. In the ES, similar proportions of treated vs control infants had ROP of stage $\geq 3$ ( $18.2 \%$ vs $18.0 \%$, respectively; $P=.24$ for severity distribution between groups). A breakdown by gestational age strata for ROP/other endpoints is presented in Table VI, Table VII, and Table VIII (available at www.jpeds.com). The number of infants who received treatment for ROP was similar between treatment groups: standard of care, 7 (all laser therapy); rhIGF-1/rhIGFBP-3, 7 (6 laser therapy, 1 anti-vascular endothelial growth factor only).

Post hoc analysis of IGF-1 levels by ROP severity $(<3, \geq 3)$ across weeks after birth showed a clear separation for mean IGF-1 profiles between treated and control infants; in the rhIGF1/rhIGFBP-3 group, an association of higher serum IGF-1 with less severe ROP was observed (Figure 3, A).

\section{Key Secondary Endpoint: Time to Discharge From Neonatal Care}

In the overall population (FAS), the median time to discharge was 82 days (range, 55-115 days) in the rhIGF-1/ rhIGFBP-3 group and 74 days (range, 51-107 days) among controls. The difference between groups was not statistically significant $(P=.37)$. In the ES, median time to discharge was 74 days in both study arms $(P=.43)$.

\section{Secondary Endpoints}

A statistically significant difference in distribution of BPD severity was observed between groups (FAS, $P=.04$; ES, $P=.02$; Table $\mathrm{V}$ ), with an apparent shift toward milder BPD cases with treatment. In the FAS, $21.3 \%$ of infants with BPD assessments (10/47) in the rhIGF-1/rhIGFBP-3 group had severe BPD vs $44.9 \%$ of controls (22/49). The difference between treatment groups was more pronounced in the ES, with $4.8 \%$ of treated infants $(1 / 21)$ with severe BPD vs $44.9 \%$ of controls.

The BPD analyses did not include the 19 all-cause deaths that occurred in the study, including 12 deaths $(20 \%)$ in the rhIGF-1/rhIGFBP-3 group and 7 deaths (12\%) in the standard care group. We conducted post hoc analyses for BPD that included all-cause deaths during the study period. In the additional analyses, deaths were grouped with severe BPD. These analyses showed that, when deaths were included, the trend for a decrease in severe BPD among treated infants remained ( $37.3 \%$ in rhIGF- $1 /$ rhIGFBP-3 group vs $51.8 \%$ in the standard of care group Table IX [available at www.jpeds.com]).

In this study, we observed a shift in the distribution of severity of BPD, which was most evident in the difference between groups in the percentage of subjects with severe BPD. If moderate cases were combined with severe cases and deaths, $52.5 \%$ of the rhIGF-1/rhIGFBP-3 group (31/59) and $60.7 \%$ of the standard care group (34/56) had BPD. When early deaths (within the first 14 days) were excluded, as suggested by Higgins et al in the 2016 National Institute of Child Health and Human Development [NICHD] workshop, ${ }^{28} 31.5 \%$ of the rhIGF-1/ rhIGFBP-3 group (17/54) vs $50.0 \%$ of the standard of care group (27/54) had severe BPD.

Post hoc analysis of IGF-1 levels by BPD severity (mild, moderate, severe) across weeks after birth showed a clear separation for mean IGF-1 profiles between treated and control infants, with a higher serum IGF-1 associated with less severe BPD in the treated group (Figure 3, B).

A smaller proportion of infants in the rhIGF-1/rhIGFBP-3 group had severe IVH (grades 3-4) than among controls (Table V): FAS, $13.1 \%$ vs $23.3 \%$, respectively; ES, $8.3 \%$ vs $23.3 \%$, respectively (not statistically significant). The numbers of IVH events were too small to explore an exposure-response relationship between IGF-1 levels and IVH grade.

rhIGF-1/rhIGFBP-3 treatment did not affect rates of change of length, weight, or head circumference compared with standard of care (Figure 4 [available at www.jpeds.com]). Similar results were seen in both the FAS and ES.

\section{Safety}

All infants had $\geq 1$ treatment-emergent AEs, with the exception of 1 infant in the rhIGF-1/rhIGFBP-3 group. For 13.1\% of treated infants (8/61), treatment-emergent AEs were considered possibly related to study drug. The most common events overall (related or unrelated) were patent ductus arteriosus 
A

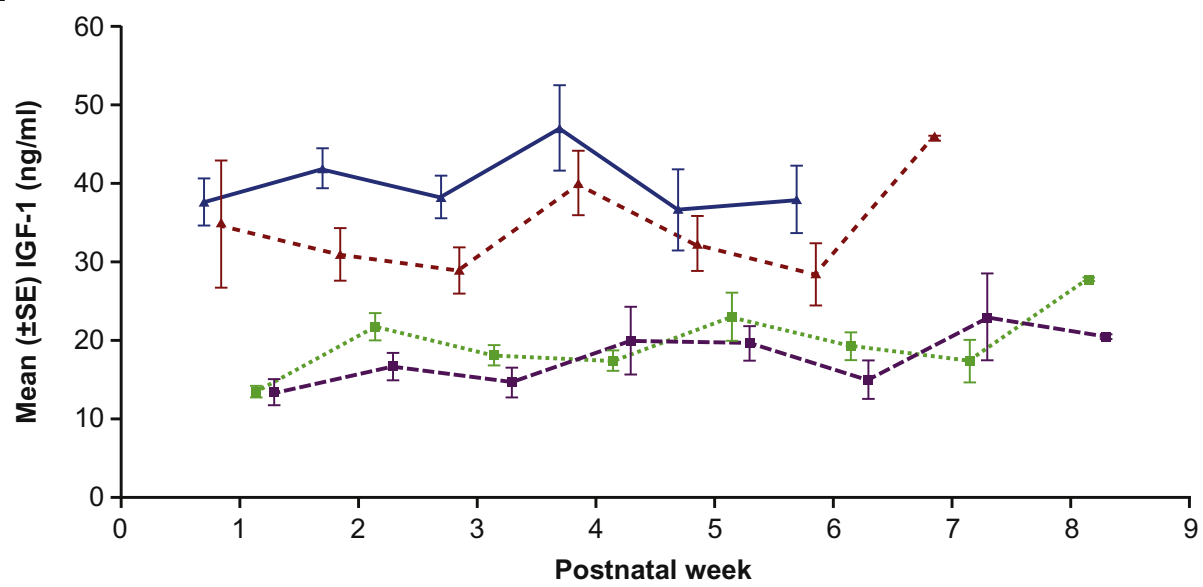

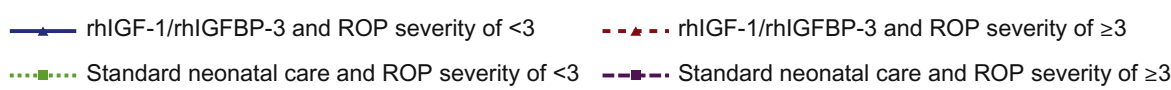

B

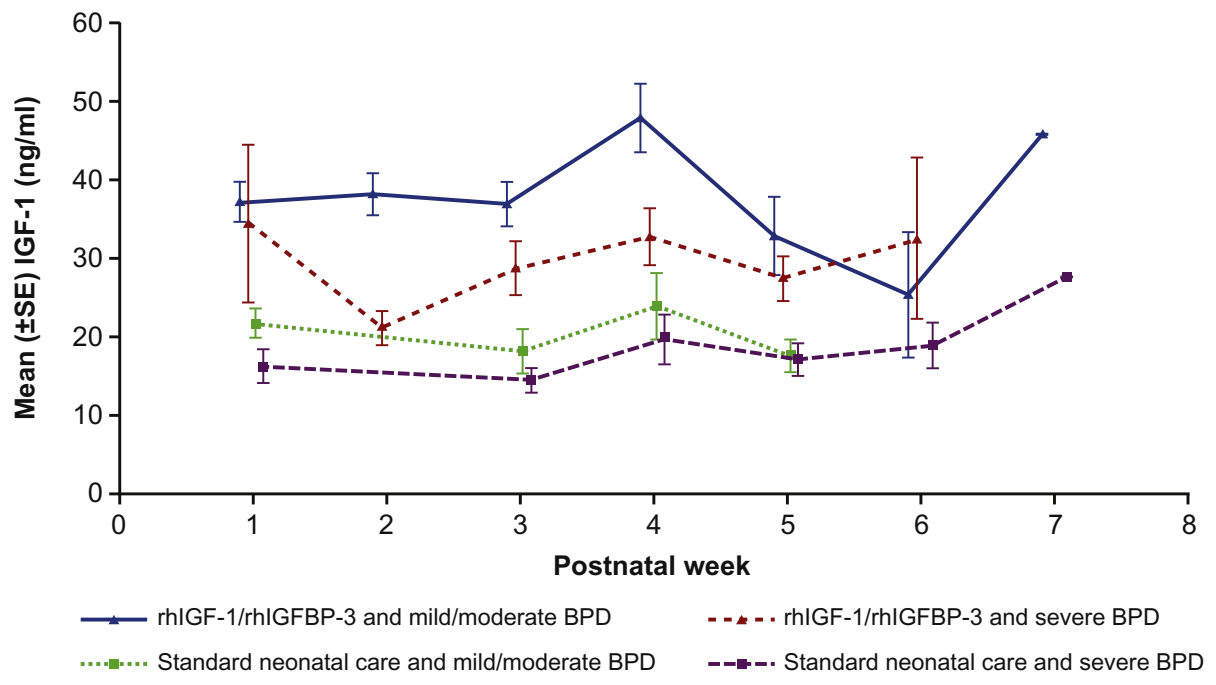

Figure 3. IGF-1 levels by A, ROP severity ${ }^{*}$ and $\mathbf{B}, \mathrm{BPD}$ severity ${ }^{\dagger}$ by postnatal week. ${ }^{*}$ Mean $( \pm \mathrm{SE})$ serum IGF-1 levels and ROP severity $(<3, \geq 3)$ in the rhIGF-1/rhIGFBP-3 and standard neonatal care groups by postnatal week. ${ }^{\dagger}$ Mean $( \pm S E)$ serum IGF-1 levels and BPD severity (mild, moderate, or severe) in the rhIGF-1/rhIGFBP-3 and standard neonatal care groups by postnatal week. Note: If an infant had multiple IGF-1 levels in a day, then IGF-1 level was averaged for the day.

(90.2\% of treated infants vs $85.0 \%$ of controls) and neonatal anemia $(75.4 \%$ vs $73.3 \%$, respectively; Table $\mathrm{X}$; available at www.jpeds.com). Additionally, $78.7 \%$ of treated infants (48/ 61 ) and $61.7 \%$ of control infants $(37 / 60)$ had SAEs.

Fatal SAEs were reported in $19.7 \%$ of treated infants (12/ 61 ) and $11.7 \%$ of control infants (7/60); none were considered treatment related (Table XI). The imbalance of deaths was concentrated in the subgroup born at a gestational age of $<26$ weeks and driven by 1 iatrogenic death owing to a misplaced umbilical catheter (which caused intra-abdominal hemorrhage leading to multiorgan failure), 1 infant with severe respiratory distress with onset before study drug infusion, and 3 more cases of necrotizing enterocolitis (NEC). Overall, NEC
AEs (fatal and nonfatal) were balanced between groups (6 infants [9.8\%] in the treated group vs 5 infants [8.3\%] in the standard care group). Further explorations revealed no apparent differences in modes of delivery, transfusions, sepsis events, antibiotic/probiotic use, or nutrition between infants with NEC who died and those who survived. In addition to NEC (which can be misclassified as a bowel perforation), 1 infant who died in the rhIGF-1/rhIGFBP-3 group had an intestinal perforation and 2 infants who died in the standard care group had intestinal perforations. Overall, including nonfatal cases, there was 1 case of intestinal perforation in the rhIGF$1 /$ rhIGFBP- 3 group, compared with 5 in the standard of care group. A full summary of safety data, including severe AEs, 
Table XI. Fatal treatment-emergent SAEs (preferred terms)

\begin{tabular}{|c|c|c|c|c|}
\hline & \multicolumn{2}{|c|}{ Standard care } & \multicolumn{2}{|c|}{ rhIGF-1/rhIGFBP-3 } \\
\hline & Gestational age $<\mathbf{2 6}$ wk & Gestational age $\geq 26$ wk & Gestational age $<\mathbf{2 6}$ wk & Gestational age $\geq 26$ wk \\
\hline $\begin{array}{l}\text { Total deaths, no. } \\
\text { Days since birth }\end{array}$ & 4 & 3 & 8 & 4 \\
\hline$\leq 7$ & $\begin{array}{c}2 \\
\text { IVH } \\
\text { Neonatal respiratory failure }\end{array}$ & 0 & $\begin{array}{c}3 \\
\text { Neonatal respiratory failure } \\
\text { Pulmonary hemorrhage } \\
\text { IVH }\end{array}$ & $\begin{array}{c}2 \\
\text { Pulmonary hypertension } \\
\text { Escherichia sepsis }{ }^{*}\end{array}$ \\
\hline$>7$ and $\leq 14$ & 0 & 0 & 0 & 0 \\
\hline$>14$ and $\leq 28$ & $\begin{array}{l}2 \\
\text { Renal failure neonatal }{ }^{\dagger} \\
\text { Citrobacter sepsis }^{\circ}\end{array}$ & $\begin{array}{c}1 \\
\text { Staphylococcal sepsis }\end{array}$ & $\begin{array}{c}4 \\
\text { Sepsis neonatal } \\
\text { Renal failure neonatal }^{\dagger} \\
\text { NEC neonatal } \\
\text { NEC neonatal }\end{array}$ & $\begin{array}{c}1 \\
\text { Renal failure neonatal }^{\dagger}\end{array}$ \\
\hline$>28$ & 0 & $\begin{array}{l}2 \\
\text { Neonatal respiratory failure } \\
\text { Intestinal obstruction }\end{array}$ & $\begin{array}{c}1 \\
\text { Neonatal respiratory failure }\end{array}$ & $\begin{array}{c}1 \\
\text { NEC neonatal }\end{array}$ \\
\hline
\end{tabular}

*Early-onset sepsis owing to Escherichia coli.

†Verbatim Terms under the Preferred Term "renal failure neonatal" were "renal insufficiency" and "acute renal failure."

$\ddagger$ Catheter-related sepsis owing to Staphylococcus epidermidis.

§Sepsis owing to Enterococcus faecalis, Staphylococcus aureus, and Staphylococcus haemolyticus.

ๆVerbatim terms under the preferred term "neonatal respiratory failure" were "respiratory insufficiency" and "respiratory failure."

and AEs of interest is provided in the Results section in Appendix 2.

\section{Discussion}

This study did not meet the primary endpoint of reducing maximum severity of ROP. However, there was a marked decrease in the proportion of rhIGF-1/rhIGFBP-3-treated infants who developed severe BPD, and a shift in patterns of BPD severity to milder cases; a similar trend was observed for IVH but was not statistically significant. rhIGF-1/rhIGFBP-3 was well-tolerated in this study; there were no safety signals. The overall results of this study support continued evaluation of rhIGF-1/rhIGFBP-3 for the prevention of complications of prematurity in extremely preterm infants.

Although a trend toward higher serum IGF-1 in rhIGF-1/ rhIGFBP-3-treated infants with no or lower stages of ROP was observed, the reason for lack of overall effect on ROP is not clear. It may be that the dosing regimen of rhIGF-1/rhIGFBP-3 requires further optimization. Alternatively, practice variability in RetCam assessments may have limited the observed treatment effect. A further consideration is the variation between sites in target oxygen saturation measures and compliance with these levels. This consideration is particularly important in light of findings from 5 landmark clinical trials, published shortly before commencement of the current study, which studied the effects of targeting lower (85\%-89\%) vs higher (91\%-95\%) oxygen saturation targets on neurodevelopmental impairment and severe ROP in extremely preterm infants. ${ }^{29-31}$ The US Surfactant, Positive Pressure, and Oxygenation Randomized Trial (SUPPORT) associated a lower oxygenation target of $85 \%-90 \%$, as compared with a higher target of 91\%-95\%, with increased mortality and decreased ROP among survivors. ${ }^{29}$ Combined findings from the Benefits of Oxygen Saturation
Targeting II (BOOST II) trials, ${ }^{30}$ conducted in the UK, Australia, and New Zealand, were largely consistent with the SUPPORT study. The investigators reported increased mortality in the lower oxygen target group vs the higher (among infants with revised oximeter software) and a lower rate of severe ROP in the lower saturation range vs the higher (among infants in the total study population). ${ }^{30}$ Conversely, the Canadian Oxygen Trial (COT) found no significant difference in mortality or the incidence of severe ROP between the lower and higher oxygen target groups. ${ }^{31}$ Findings from the SUPPORT and BOOST II trials led to changes in neonatal clinical practice, where the risk of ROP needed to be considered against the risk of increased mortality, with the result that many centers across countries adopted higher oxygen target ranges. More recent studies have reported increased rates and severity of ROP among extremely preterm infants after changing from lower to higher oxygen target ranges. ${ }^{32,33}$ It is possible that higher oxygen target ranges used in centers in the current study may have affected the observed incidences of ROP in the study population.

The key secondary endpoint of time to discharge from neonatal care also was not statistically different between groups. However, it is difficult to draw conclusions from these data because assessment of length of stay in intensive care is easily confounded. There also was a lack of effect of rhIGF-1/ rhIGFBP- 3 on growth measures, which could have been confounded by nutritional differences across sites; unfortunately, nutrition data were not recorded consistently, precluding further analysis of a potential effect.

By contrast, the shift in severity distribution of BPD was marked and suggests a hypothesis-generating trend with higher serum IGF-1. The rate of IVH events was too low to evaluate correlations with IGF-1 levels, but a similar trend toward a decrease in grades 3-4 IVH in the ES vs the FAS was observed. Although it remains unclear why such a marked effect was seen 
for BPD relative to ROP, these observations support the hypothesis that increasing serum IGF-1 levels can decrease the severity of complications of prematurity.

An analysis of the achieved serum IGF-1 levels indicates that attainment of target levels could be further optimized to potentially improve outcomes. An interim pharmacokinetic analysis in the first 10 treated infants supported the appropriateness of the $250 \mu \mathrm{g} / \mathrm{kg} / 24$ hours dose to achieve IGF-1 target levels. ${ }^{20}$ However, in the treated population, although the proportion of IGF-1 measurements within target was substantially greater than among controls, fewer than one-half of infants $(28 / 61$ [45.9\%]) achieved $\geq 70 \%$ of IGF- 1 measurements within the target range (see the Results section in Appendix 2). It is possible that the slightly lower than anticipated target attainment could relate to technical aspects of drug administration or that intercurrent proinflammatory states could have led to fluctuations in IGF-1 levels. ${ }^{34}$ Alternatively, these observations may point to a need for further dose optimization.

The observed safety profile of rhIGF- $1 /$ rhIGFBP- 3 was encouraging. There was an imbalance in deaths between the treatment arms concentrated in the subgroup with a gestational age of <26 weeks; however, careful evaluation of the causes of death by an independent data monitoring committee did not raise safety concerns (see the Results section in Appendix 2). With regard to other safety considerations, despite the duration of intravenous infusion, data collected to date across rhIGF-1/ rhIGFBP-3 clinical trials have shown no signs of an increase in pathogen-confirmed sepsis. Also in the current study, the proportion of infants with hypoglycemia was similar between groups. Of note, rhIGF-1/rhIGFBP-3 was associated with a lower incidence of hyperglycemia relative to standard care, suggesting possible improvements in glycemic control. A previous phase of the study (B/C) found that rhIGF-1/rhIGFBP-3 was well-tolerated in extremely preterm infants and that the incidence of AEs was similar for infants treated with rhIGF1/rhIGFBP-3 vs control infants. ${ }^{35}$ Further, consistent with the current trial, rates of hypoglycemia were similar between groups in the phase B/C study. These outcomes will be of interest for further investigation.

The limitations of this study included the smaller than anticipated number of infants eligible for inclusion in the ES, albeit an arbitrary a priori definition. Another limitation was the randomization by gestational age centrally and not by study site, which resulted in an imbalance between gestational age strata at high enrolling sites, and may have been an additional confounder. Additionally, there were technical challenges to performing certain assessments (eg, RetCam) and variability of practices across and within sites. The analysis of AEs was limited by some reporting inconsistency, largely owing to a lack of international consensus on defining and classifying AEs in infants based on their severity. A further consideration is that infants who died were not included in the analyses, and this factor may have had an impact on our findings related to the degree of difference in severe BPD between the 2 groups. However, post hoc analyses showed similar, although attenuated, results when all-cause death was included with severe BPD as an outcome. Although the prevalence of ROP, BPD, and IVH was comparable with the observed prevalence in the extremely preterm population, ${ }^{36,37}$ the sample size was relatively small. The latter limitation obviously precludes the evaluation of a possible confounding effect of mortality on differences in respiratory morbidity between study groups at a gestational age of 36 weeks. A larger investigation that examines a higher dose IGF-I with more standardized and harmonized approaches to safety assessments is needed to clarify this issue, including the evaluation of treatment effects on NEC. Preclinical models indicate that IGF-I supplementation and subsequent enhancement of vascular endothelial growth factor receptor-2 signaling may have a preventive effect on development of NEC. ${ }^{38-42}$ Higher levels of plasma IGF-1 were also associated with reduced incidence of NEC in a prospective analysis of very low birth weight infants in the NIRTURE study. ${ }^{43}$ The administration of IGF-1/ IGFBP3 would not be expected to increase the risk of NEC.

Of note, there were additional protocol limitations associated with the methodology used to assess presence of IVH (a single reader of cranial ultrasound examinations, grading only by the Papile/Bowerman method ${ }^{25,26}$ ), which may have impacted the frequency of the various grades seen in both treatment groups. Post hoc analyses are ongoing using an adjudicated reader and 2 additional scoring methods $s^{44,45}$ for the assessment of ultrasound scans to evaluate whether the frequency of the various grades varied as a function of the scoring method; details of the comparison (also including magnetic resonance imaging data) will be reported separately.

Based on the results of this study and given the clear unmet need for therapies to decrease the overall morbidity burden in extremely preterm infants, ${ }^{46-49}$ continued investigation of rhIGF-1/rhIGFBP-3 for the prevention of complications of prematurity is planned in a larger clinical trial. The protocol for this study is in development, with the prevention of the onset of chronic lung disease (indicated by reductions in respiratory complications) at a corrected age of 12 months as the primary endpoint, and a decrease in the severity of BPD at a PMA of 36 weeks and IVH severity at a PMA of 40 weeks as separate key secondary endpoints. Of importance, long-term outcomes after short-term exposure to rhIGF-1/rhIGFBP-3 also are being investigated in an extension study (PEDAL; NCT02386839) over 5 years.

We thank Rui Tang, an employee of Shire, who provided assistance with additional statistical analysis. We also thank Valérie Boissel, PhD, and Rosalind Bonomally, MSc, of Excel Scientific Solutions, who provided medical writing assistance funded by Shire. The authors thank the infants, their families, and the investigators/contributors who participated in this study (list of participants available at www.jpeds.com [Appendix 1]).

Submitted for publication Feb 5, 2018; last revision received Oct 12, 2018; accepted Oct 17, 2018

Reprint requests: David Ley, MD, PhD, Lund University, Skåne University Hospital, Department of Clinical Sciences Lund, Pediatrics, Lund 211 85, Sweden. E-mail: david.ley@med.lu.se

\section{References}

1. Langford K, Nicolaides K, Miell JP. Maternal and fetal insulin-like growth factors and their binding proteins in the second and third trimesters of human pregnancy. Hum Reprod 1998;13:1389-93. 
2. Hellström A, Ley D, Hansen-Pupp I, Hallberg B, Löfqvist C, van Marter $\mathrm{L}$, et al. Insulin-like growth factor 1 has multisystem effects on foetal and preterm infant development. Acta Paediatr 2016;105:576-86.

3. Hansen-Pupp I, Löfqvist C, Polberger S, Niklasson A, Fellman V, Hellstrom $\mathrm{A}$, et al. Influence of insulin-like growth factor I and nutrition during phases of postnatal growth in very preterm infants. Pediatr Res 2011;69:44853.

4. Lineham JD, Smith RM, Dahlenburg GW, King RA, Haslam RR, Stuart MC, et al. Circulating insulin-like growth factor I levels in newborn premature and full-term infants followed longitudinally. Early Hum Dev 1986;13:37-46.

5. Hellström A, Engstrom E, Hård AL, Albertsson-Wikland K, Carlsson B, Niklasson A, et al. Postnatal serum insulin-like growth factor I deficiency is associated with retinopathy of prematurity and other complications of premature birth. Pediatrics 2003;112:1016-20.

6. Pérez-Muñuzuri A, Fernández-Lorenzo JR, Couce-Pico ML, Blanco-Teijeiro MJ, Fraga-Bermúdez JM. Serum levels of IGF1 are a useful predictor of retinopathy of prematurity. Acta Paediatr 2010;99:51925.

7. Löfqvist C, Engström E, Sigurdsson J, Hard AL, Niklasson A, Ewald U, et al. Postnatal head growth deficit among premature infants parallels retinopathy of prematurity and insulin-like growth factor-1 deficit. Pediatrics 2006;117:1930-8.

8. Löfqvist C, Hellgren G, Niklasson A, Engström E, Ley D, Hansen-Pupp I. Low postnatal serum IGF-I levels are associated with bronchopulmonary dysplasia (BPD). Acta Paediatr 2012;101:1211-6.

9. Klevebro S, Lundgren P, Hammar U, Smith LE, Bottai M, Domellof M, et al. Cohort study of growth patterns by gestational age in preterm infants developing morbidity. BMJ Open 2016;6:e012872.

10. Hellstrom A, Perruzzi C, Ju M, Engström E, Hård AL, Liu JL, et al. Low IGF-I suppresses VEGF-survival signaling in retinal endothelial cells: direct correlation with clinical retinopathy of prematurity. Proc Natl Acad Sci USA 2001;98:5804-8.

11. Vanhaesebrouck S, Daniëls H, Moons L, Vanhole C, Carmeliet P, De Zegher F. Oxygen-induced retinopathy in mice: amplification by neonatal IGF-I deficit and attenuation by IGF-I administration. Pediatr Res 2009;65:30710.

12. Jin ZA, Jin ZY, Chi YX, Lu JR. Effects of recombinant human insulinlike growth factor-1 on the expression of Clara cell secretory protein in lung of hyperoxia-exposed newborn rats. Zhonghua Er Ke Za Zhi 2007;45:369-73. [in Chinese].

13. Jakkula M, Le Cras TD, Gebb S, Hirth KP, Tuder RM, Voelkel NF, et al. Inhibition of angiogenesis decreases alveolarization in the developing rat lung. Am J Physiol Lung Cell Mol Physiol 2000;279:L600-7.

14. De Paepe ME, Mao Q, Powell J, Rubin SE, DeKoninck P, Appel N, et al. Growth of pulmonary microvasculature in ventilated preterm infants. Am J Respir Crit Care Med 2006;173:204-11.

15. Lekic T, Flores J, Klebe D, Doycheva D, Rolland WB, Tang J, et al. Intranasal IGF-1 reduced rat pup germinal matrix hemorrhage. Acta Neurochir Suppl 2016;121:209-12.

16. Ley D, Hansen-Pupp I, Niklasson A, Domellof M, Friberg LE, Borg J, et al. Longitudinal infusion of a complex of insulin-like growth factor-I and IGF-binding protein-3 in five preterm infants: pharmacokinetics and shortterm safety. Pediatr Res 2013;73:68-74.

17. Hallberg B, Hansen-Pupp I, Chung J-K, Sharma J, Fetterly G, Mascelli M, et al. Determination of optimal dosing of recombinant human IGF-1/ IGFBP-3 to establish and maintain physiological intrauterine serum IGF-1 levels in preterm infants. J Pediatr Neonat Individual Med 2015;4: e040212.

18. Lassarre C, Hardouin S, Daffos F, Forestier F, Frankenne F, Binoux M. Serum insulin-like growth factors and insulin-like growth factor binding proteins in the human fetus: relationships with growth in normal subjects and in subjects with intrauterine growth retardation. Pediatr Res 1991;29:219-25.

19. Bang P, Westgren M, Schwander J, Blum WF, Rosenfeld RG, Stangenberg M. Ontogeny of insulin-like growth factor-binding protein-1, -2 , and -3 : quantitative measurements by radioimmunoassay in human fetal serum. Pediatr Res 1994;36:528-36.
20. Chung J-K, Hallberg B, Hansen-Pupp I, Graham MA, Fetterly G, Sharma $\mathrm{J}$, et al. Development and verification of a pharmacokinetic model to optimize physiologic replacement of rhIGF-1/rhIGFBP-3 in preterm infants. Pediatr Res 2017;81:504-10.

21. International Committee for the Classification of Retinopathy of Prematurity. The International Classification of Retinopathy of Prematurity revisited. Arch Ophthalmol 2005;123:991-9.

22. Early Treatment For Retinopathy Of Prematurity Cooperative Group. Revised indications for the treatment of retinopathy of prematurity: results of the early treatment for retinopathy of prematurity randomized trial. Arch Ophthalmol 2003;121:1684-94.

23. Walsh MC, Szefler S, Davis J, Allen M, Van Marter L, Abman S, et al. Summary proceedings from the bronchopulmonary dysplasia group. Pediatrics 2006;117:S52-6.

24. Jobe AH, Bancalari E. Bronchopulmonary dysplasia. Am J Respir Crit Care Med 2001;163:1723-9.

25. Papile LA, Burstein J, Burstein R, Koffler H. Incidence and evolution of subependymal and intraventricular hemorrhage: a study of infants with birth weights less than 1,500 gm. J Pediatr 1978;92:529-34.

26. Bowerman RA, Donn SM, Silver TM, Jaffe MH. Natural history of neonatal periventricular/intraventricular hemorrhage and its complications: sonographic observations. AJR Am J Roentgenol 1984;143:104152.

27. Austeng D, Kallen KB, Ewald UW, Jakobsson PG, Holmstrom GE. Incidence of retinopathy of prematurity in infants born before 27 weeks' gestation in Sweden. Arch Ophthalmol 2009;127:1315-9.

28. Higgins RD, Jobe AH, Koso-Thomas M, Bancalari E, Viscardi RM, Hartert TV, et al. Bronchopulmonary dysplasia: executive summary of a workshop. J Pediatr 2018;197:300-8.

29. Carlo WA, Finer NN, Walsh MC, Rich W, Gantz MG, Laptook AR, et al. Target ranges of oxygen saturation in extremely preterm infants. N Engl J Med 2010;362:1959-69.

30. Stenson BJ, Tarnow-Mordi WO, Darlow BA, Simes J, Juszczak E, Askie $\mathrm{L}$, et al. Oxygen saturation and outcomes in preterm infants. $\mathrm{N}$ Engl J Med 2013;368:2094-104.

31. Schmidt B, Whyte RK, Asztalos EV, Moddemann D, Poets C, Rabi Y, et al. Effects of targeting higher vs lower arterial oxygen saturations on death or disability in extremely preterm infants: a randomized clinical trial. JAMA 2013;309:2111-20.

32. Manley BJ, Kuschel CA, Elder JE, Doyle LW, Davis PG. Higher rates of retinopathy of prematurity after increasing oxygen saturation targets for very preterm infants: experience in a single center. J Pediatr 2016;168:2424.

33. Lundgren P, Hard AL, Wilde A, Lofqvist C, Smith LEH, Hellstrom A. Implementing higher oxygen saturation targets reduced the impact of poor weight gain as a predictor for retinopathy of prematurity. Acta Paediatr 2018;107:767-73.

34. Hansen-Pupp I, Hellström-Westas L, Cilio CM, Andersson S, Fellman V, Ley D. Inflammation at birth and the insulin-like growth factor system in very preterm infants. Acta Paediatr 2007;96:830-6.

35. Hansen-Pupp I, Hellstrom A, Hamdani M, Tocoian A, Kreher NC, Ley $\mathrm{D}$, et al. Continuous longitudinal infusion of rhIGF-1/rhIGFBP-3 in extremely preterm infants: evaluation of feasibility in a phase II study. Growth Horm IGF Res 2017;36:44-51.

36. Stoll BJ, Hansen NI, Bell EF, Shankaran S, Laptook AR, Walsh MC, et al. Neonatal outcomes of extremely preterm infants from the NICHD Neonatal Research Network. Pediatrics 2010;126:443-56.

37. Stoll BJ, Hansen NI, Bell EF, Walsh MC, Carlo WA, Shankaran S, et al. Trends in care practices, morbidity, and mortality of extremely preterm neonates, 1993-2012. JAMA 2015;314:1039-51.

38. Bowker RM, Yan X, Managlia E, Liu SXL, Marek C, Tan XD, et al. Dimethyloxalylglycine preserves the intestinal microvasculature and protects against intestinal injury in a neonatal mouse NEC model: role of VEGF signaling. Pediatr Res 2018;83:545-53.

39. Dong CX, Zhao W, Solomon C, Rowland KJ, Ackerley C, Robine S, et al. The intestinal epithelial insulin-like growth factor-1 receptor links glucagon-like peptide-2 action to gut barrier function. Endocrinology 2014;155:370-9. 
40. Drucker DJ, DeForest L, Brubaker PL. Intestinal response to growth factors administered alone or in combination with human [Gly2]glucagon-like peptide 2. Am J Physiol 1997;273:G1252-62.

41. Tian R, Liu SX, Williams C, Soltau TD, Dimmitt R, Zheng X, et al. Characterization of a necrotizing enterocolitis model in newborn mice. Int J Clin Exp Med 2010;3:293-302.

42. Yan X, Managlia E, Liu SX, Tan XD, Wang X, Marek C, et al. Lack of VEGFR2 signaling causes maldevelopment of the intestinal microvasculature and facilitates necrotizing enterocolitis in neonatal mice. Am J Physiol Gastrointest Liver Physiol 2016;310:G716-25.

43. Beardsall K, Vanhaesebrouck S, Frystyk J, Ogilvy-Stuart AL, Vanhole C, van Weissenbruch $\mathrm{M}$, et al. Relationship between insulin-like growth factor I levels, early insulin treatment, and clinical outcomes of very low birth weight infants. J Pediatr 2014;164:1038-44, e1.

44. Bassan H, Benson CB, Limperopoulos C, Feldman HA, Ringer SA, Veracruz E, et al. Ultrasonographic features and severity scoring of periventricular hemorrhagic infarction in relation to risk factors and outcome. Pediatrics 2006;117:2111-8.

45. Dudink J, Lequin M, Weisglas-Kuperus N, Conneman N, van Goudoever JB, Govaert P. Venous subtypes of preterm periventricular haemorrhagic infarction. Arch Dis Child Fetal Neonatal Ed 2008;93:F201-6.

46. Gough A, Spence D, Linden M, Halliday HL, McGarvey LP. General and respiratory health outcomes in adult survivors of bronchopulmonary dysplasia: a systematic review. Chest 2012;141:1554-67.

47. Gough A, Linden MA, Spence D, Halliday HL, Patterson CC, McGarvey L. Executive functioning deficits in young adult survivors of bronchopulmonary dysplasia. Disabil Rehabil 2015;37:1940-5.

48. Iyengar A, Davis JM. Drug therapy for the prevention and treatment of bronchopulmonary dysplasia. Front Pharmacol 2015;6:12.

49. McCrea HJ, Ment LR. The diagnosis, management, and postnatal prevention of intraventricular hemorrhage in the preterm neonate. Clin Perinatol 2008;35:777-92. 


\section{Detailed affiliations}

From the ${ }^{1}$ Skane University Hospital, Department of Clinical Sciences Lund, Pediatrics, Lund University, Lund, Sweden;

${ }^{2}$ Department of Neonatology, Department of Clinical Science, Intervention and Technology (CLINTEC), Karolinska Institute and Karolinska University Hospital, Stockholm, Sweden;

${ }^{3}$ Careggi University Hospital of Florence, University of Florence, Florence, Italy;

${ }^{4}$ Genova Neonatal Intensive Care Unit, Istituto Giannina Gaslini, Genova, Italy;

${ }^{5}$ Department of Academic Neonatology, UCL EGA Institute for Women's Health, UCL, London, United Kingdom;

${ }^{6}$ Department of Pediatrics and the Wellcome Trust-MRC Institute of Metabolic Science, University of Cambridge, Cambridge, United Kingdom;

${ }^{7}$ Neonatal Perinatal Medicine, Department of Pediatrics, The Children's Hospital at the University of Oklahoma Health Sciences Center, Oklahoma City, OK;

${ }^{8}$ Department of Pediatrics, Brody School of Medicine, East Carolina University, Greenville, NC;
${ }^{9}$ St Mary's Hospital, Central Manchester University Hospitals NHS Foundation Trust, Manchester Academic Health Science Centre and Division of Developmental Biology and Medicine, School of Medical Sciences, University of Manchester, Manchester, United Kingdom;

${ }^{10}$ The Department of Pediatrics and Ophthalmology, University of Wisconsin, Madison, WI;

${ }^{11}$ Neonatal Intensive Care Unit, St Peter's Hospital, Chertsey, Surrey, United Kingdom;

${ }^{12}$ Department of Woman and Child Health, University Hospital A. Gemelli, IRCCS, Rome, Italy;

${ }^{13}$ Department of Pediatrics, Division of Neonatology, VU University Medical Center, Amsterdam, The Netherlands;

${ }^{14}$ Global Clinical Development, Rare Metabolic Diseases, Shire, Lexington, MA;

${ }^{15} \mathrm{Global}$ Clinical Development, Rare Metabolic Diseases, Shire, Zug, Switzerland;

${ }^{16}$ Institute of Translational Medicine, University of Liverpool, Liverpool, United Kingdom;

${ }^{17}$ Harvard Medical School, Boston Children's Hospital, Boston, MA; and

${ }^{18}$ Institute of Neuroscience and Physiology, Sahlgrenska Academy, Gothenburg, Sweden 
Appendix 1

\section{Study Investigators and Other Contributors by Clinical Site/Affiliation}

\section{Clinical sites \\ Lund University, Skane University Hospital, Department of Clinical Sciences Lund, Pediatrics, Lund, Sweden \\ Department of Neonatology, Department of Clinical Science, Intervention and Technology (CLINTEC), Karolinska Institute and Karolinska University Hospital, Stockholm, Sweden \\ Careggi University Hospital of Florence, University of Florence, Florence, Italy}

\section{UCL EGA Institute for Women's Health, London, UK}

The Department of Pediatrics and the Wellcome-Trust MRC Institute of Metabolic Science, University of Cambridge, Cambridge, UK

The Children's Hospital at the University of Oklahoma Health Sciences Center, Oklahoma City, OK

East Carolina University, Greenville, NC

St Mary's Hospital, Central Manchester University NHS Foundation Trust, Manchester Academic Health Science Centre and Division of Developmental Biology \& Medicine, School of Medical Sciences, University of Manchester, Manchester, UK

Departments of Pediatrics and Ophthalmology, University of Wisconsin, Madison, WI

Neonatal Intensive Care Unit, St Peter's Hospital, Chertsey, Surrey, UK Department of Woman and Child Health, University Hospital A. Gemelli, Rome, Italy

VU University Medical Center, Amsterdam, the Netherlands Institute of Translational Medicine, University of Liverpool, Liverpool, UK Department for Women's and Children's Health, University of Padua, Padua, Italy Department of Pediatrics, University Hospitals Coventry and Warwickshire NHS Trust, Coventry, UK

University of Mississippi Medical Center, Jackson, MS

University of South Alabama Children's \& Women's Hospital, Mobile, AL

Neonatal-Perinatal Medicine, Mercy and St. Luke's Hospitals, St. Louis, M0

Department of Neonatology, Poznan University of Medical Sciences, Poznan, Poland

Additional contributors (not affiliated with study sites)

Affiliation

University of Rochester Medical Center, Rochester, NY

Department of Pediatric Ophthalmology and Strabismus, Ludwig-MaximiliansUniversity München, Munich, Germany

\section{Study investigators/contributors}

Margareta Gebka, RN; Ann-Cathrine Berg, RN

Mireille Vanpee, MD; Dirk Wackernagel, MD; Stefan Löfgren, MD

Chiara Poggi, MD; Elena Gozzini, MD; Tommaso Bianconi, MD; Saverio Frosini, MD; Simone Pratesi, MD; luri Corsini MD; Venturella Vangi, MD; Ada Kura, PhD Rashmi Gandhi, MBBS, MRCPCH; Joanna Lawson, FRCS(Ed), FRCOphth; Gina Burquis, RN

Lynn Thomson, RSCN

Michael Siatkowski, MD; Birju Shah, MD; Michael McCoy; Michelle Blunt; Kelly Satnes; Kimberly Benjamin; Lindsay DePace

Devon Kuehn, MD, Sherry L. Moseley, RN; Ryan Moore, MD

S. Nedungadi, MRCPCH; S. Biswas, FRCOphth; G. Ciotti, MD; V. Tang, MD; A. Hendrickson; K. Dockery; N. Booth

Michael Struck, MD; De-Ann Pillers, MD, PhD; Yasmin Bradfield, MD; Melanie Schmitt, MD; Erica Riedesel, MD

Nicky Holland, RN; Edit Molnar, MD

Costantino Romagnoli, MD; Velia Purcaro, MD; Francesca Serrao, MD; Patrizia Papacci, MD; Mikael Ghennet Tesfagabir, MD; Rossella lannotta, MD; Maria Sofia Cori, MD; Antonio Baldascino, MD; Cecilia Zuppi, MD; Giovanni Luca Scaglione, MSc, PhD; Andrea Cocci, MLT; Elisa De Paolis, MSc; Cesare

Colosimo, MD; Tommaso Verdolotti, MD; Marino Gentile; Marta Romagnoli Dana Yumani, MD; Annemieke de Lang

Patrick McGowan, RGN; Karen Harvey, RSCN; Joanne Windrow, RSCN

Paola Lago, MD

Prakash Satodia, MD

Abhay Bhatt, MD

Fabien Eyal, MD

Erzsebet Jung, MD

Janusz Gadzinowski, MD

\section{Contributor}

Matthew D. Gearinger, MD; Mina M. Chung, MD; Henry Wang, MD Birgit Lorenz, MD

\section{Appendix 2}

\section{Methods}

Safety Monitoring. A clinical study monitor ensured that the investigation was conducted according to protocol design and regulatory requirements through frequent site visits and communications. Infant safety was monitored on a continuous basis until the last infant completed the last scheduled study visit/ assessment, and quarterly safety review meetings were held throughout the study. Safety data collected during the trial were reported annually to competent authorities in the form of a Development Safety Update Report. Additionally, an independent data monitoring committee provided an ongoing review and assessment of safety data. A special data monitoring committee meeting was to be convened if the safety-related stopping rules (ie, if a death occurred that was considered possibly or probably related to the study drug) were met.
Interim Analyses. Two interim analyses were planned and conducted. The first was an analysis of dosing/target attainment conducted when 10 treated infants had completed the rhIGF1/IGFBP-3 dosing phase of the study (reported previously by Chung et $\mathrm{al}^{1}$ ). In the second, a conditional power analysis was performed on unmasked data when 60 infants had completed the study or withdrew early. The analysis was performed by an external independent statistician to assess the appropriateness of the sample size and assumptions made regarding the distribution of the maximum severity of ROP.

Concomitant Medications. Predefined medications (including hydrocortisone, betamethasone, dexamethasone, ibuprofen, dopamine, dobutamine, epinephrine, budesonide, furosemide, nitric oxide, Curosurf/other surfactants, indomethacin, and other medications given to treat AEs) and 
procedures administered to infants from time of informed consent through to a PMA of $40^{4 / 7}$ weeks were regarded as permitted. Treatment with fresh frozen plasma, which is associated with a short-term increase of serum concentrations of IGF- $1,{ }^{2}$ was permitted and recorded. Anti-vascular endothelial growth factor medication and rh erythropoietin were prohibited. Delivery of parenteral/enteral nutrition (including glucose) was performed according to local guidelines.

IGF-1 Blood Sampling. Blood samples for IGF-1 measurement were obtained at baseline (predose), 12 hours \pm 30 minutes, and 24 hours \pm 30 minutes after the infusion started, then every $72 \pm 1$ hours until a PMA of $29^{6 / 7}$ weeks, and then 1 hour \pm 30 minutes after the infusion stopped for treated infants. Controls were tested at baseline (day of birth), 12 hours \pm 30 minutes, 24 hours \pm 30 minutes, and then every 168 \pm 1 hours after baseline until a PMA of $29^{6 / 7}$ weeks. Additional sampling occurred at PMA 32, 36, and 40 weeks. IGF-1 was determined locally by a validated ELISA (Mediagnost $\mathrm{GmbH}$, Reutlingen, Germany), and in a central laboratory by radioimmunoassay (PPD Laboratories, Richmond, Virginia). ${ }^{3}$

Safety Assessments. Hypoglycemia was defined within the trial as plasma glucose levels of $<2.5 \mathrm{mmol} / \mathrm{L}$ measured during predefined schedules of blood glucose monitoring (see Blood Glucose Monitoring section), and from blood glucose measurements performed on clinical indication. Hyperglycemia was defined as plasma glucose levels of $>10 \mathrm{mmol} / \mathrm{L}$. Echocardiography was interpreted by a pediatric cardiologist to define presence of clinically significant patent ductus arteriosus on postnatal days 2 and 4 , and according to clinical judgment after these time points. All infants were assessed for tonsillar hypertrophy by visual examination of their tonsils during a weekly physical examination and at term age (PMA of 40 weeks) by a pediatric specialist.

\section{Blood Glucose Monitoring.}

rhIGF-1/rhIGFBP-3 Group. For infants who were fed every 2 hours or who were fed intravenously or through continuous enteral feed, blood glucose measurement was performed every 4 hours during the first 72 hours (days 1-3) after starting infusion with rhIGF-1/rhIGFBP-3. For infants who were fed every 3 hours, blood glucose was measured every 3 hours during the first 72 hours (days 1-3) after starting infusion with rhIGF-1/rhIGFBP-3. During days 4-7, blood glucose was measured every 6 hours for those infants who were fed either every 2 or every 3 hours. After the first 7 days of the infusion, blood glucose was analyzed twice daily until the completion of infusion (PMA of $29^{6 / 7}$ weeks). Thereafter, blood glucose was measured weekly until the end of the study. If blood glucose was $<3 \mathrm{mmol} / \mathrm{L}$ during ongoing rhIGF-1/rhIGFBP-3 infusion and more frequent monitoring was deemed necessary based on the clinical judgment of the investigator, a blood glucose sample was then taken every hour until a blood glucose of $\geq 3 \mathrm{mmol} / \mathrm{L}$ was reached. Clinical sites had specific protocols in place to monitor hypoglycemia.
Standard Neonatal Care Group. Blood glucose was analyzed every 6 hours for the first 7 days. Thereafter, it was analyzed twice daily until a PMA of $29^{6 / 7}$ weeks, provided that blood was available for sampling. If blood was not available, the sample collection interval was increased. After PMA $29^{6 / 7}$ weeks, blood glucose was measured weekly until the end of the study.

Statistical Analyses. The primary endpoint between the 2 groups was analyzed using a generalized Cochran-MantelHaenszel row means score statistic with modified ridit scores adjusting for gestational age strata. This statistical test generates an estimate of an association between an exposure and an outcome after adjusting for or taking into account confounding factors. The sample size of 80 evaluable infants also was to provide adequate power for the key secondary endpoint of time to discharge from neonatal care, for which the difference between the 2 treatment groups was tested using the stratified version of the Wilcoxon rank-sum test and adjusted for gestational age status. In the event of death, time to discharge was imputed using the median value of all infants with available data within each gestational age strata. The comparison between treatment groups for ordered category of BPD (absent, mild, moderate, severe) at PMA 36 weeks was made using Cochran-Mantel-Haenszel row mean score statistics with modified ridit scores adjusting for gestational age strata. The grade of the hemorrhage (grades 1-4) was summarized descriptively by treatment group and gestational age strata. The difference in the distribution of IVH severity seen between the rhIGF-1/rhIGFBP-3 (FAS or ES) and standard care groups was analyzed in a post hoc analysis using Cochran-MantelHaenszel row mean score statistics. Weight, length, and head circumference were analyzed separately, using a linear mixedmodel repeated measurement analysis over all postbaseline visits, with change from baseline in each parameter as the outcome variable. The model included treatment time (days), treatment by time interaction, gestational age strata as a fixed effect, infant as a random effect, and baseline value as covariate. Time (days) was calculated relative to the date of the baseline assessment and was used as a continuous covariate.

\section{Results}

Serum IGF-1 Levels. For rhIGF-1/rhIGFBP-3-treated infants, $66.2 \%$ of IGF- 1 measurements were within the targeted physiological intrauterine range $(28-109 \mu \mathrm{g} / \mathrm{L})$ vs $6.3 \%$ for the standard care group (predose data and data after the end of the final infusion were excluded). Very few IGF-1 measurements $(1.5 \%)$ in treated infants were above the upper bound of the targeted range. Figure 2 shows the mean (SD) serum IGF-1 concentrations over the duration of the study in both the rhIGF-1/rhIGFBP-3 and standard care groups; mean concentrations were within target range during the infusion period for treated infants and below range for the standard care group. The onset of endogenous IGF-1 production was estimated between weeks 30 and 32 (corresponding approximately with cessation of treatment), after which both groups had mean IGF-1 levels within the target range. 


\section{Additional Safety Results.}

Severe AEs. In the rhIGF-1/rhIGFBP-3 vs standard care groups, $73.8 \%$ of infants $(45 / 61)$ vs $65.0 \%$ of infants (39/60) experienced SAEs, respectively. Only 1 treated infant (1.6\%) had 2 SAEs considered possibly related to study drug (1 AE of IVH and 1 separate AE of apnea).

Discontinuations Owing to AEs. A total of 20 infants (11 [18\%] in the rhIGF-1/rhIGFBP-3 group and $9[15 \%]$ in the standard care group) discontinued the study owing to treatment-emergent AEs, which were fatal SAEs in $90 \%$ of infants (18/20). One additional infant in the treated group had an SAE with fatal outcome, but the primary reason for discontinuation was withdrawal of consent.

AEs of Interest. The frequency of pathogen-confirmed sepsis was similar between the rhIGF-1/rhIGFBP-3 and standard care groups ( $65.9 \%$ vs $67.4 \%$, respectively). Coagulase-negative staphylococcal sepsis was reported in similar percentages of infants in each group: $36.4 \%$ vs $37.2 \%$ in the rhIGF-1/ rhIGFBP-3 and standard care groups, respectively. Hypogly- cemia occurred in a similar proportion in each group: $29.5 \%$ of infants (18/61) in the rhIGF-1/rhIGFBP-3 group had AEs of hypoglycemia (considered possibly related to treatment for 4 infants) vs $31.7 \%$ (19/60) in the standard care group. Additionally, 39.3\% of infants (24/61) in the rhIGF-1/rhIGFBP-3 group had AEs of hyperglycemia vs $48.3 \%$ (29/60) in the standard care group (Table VIII). There were no cases of intracranial hypertension or tonsillar hypertrophy in either group.

\section{References}

1. Chung J-K, Hallberg B, Hansen-Pupp I, Graham MA, Fetterly G, Sharma J, et al. Development and verification of a pharmacokinetic model to optimize physiologic replacement of rhIGF-1/rhIGFBP-3 in preterm infants. Pediatr Res 2017;81:504-10.

2. Hansen-Pupp I, Engstrom E, Niklasson A, Berg AC, Fellman V, Lofqvist C, et al. Fresh-frozen plasma as a source of exogenous insulin-like growth factor-I in the extremely preterm infant. J Clin Endocrinol Metab 2009;94:477-82.

3. Blum WF, Breier BH. Radioimmunoassays for IGFs and IGFBPs. Growth Regul 1994;1(Suppl 1):11-9.

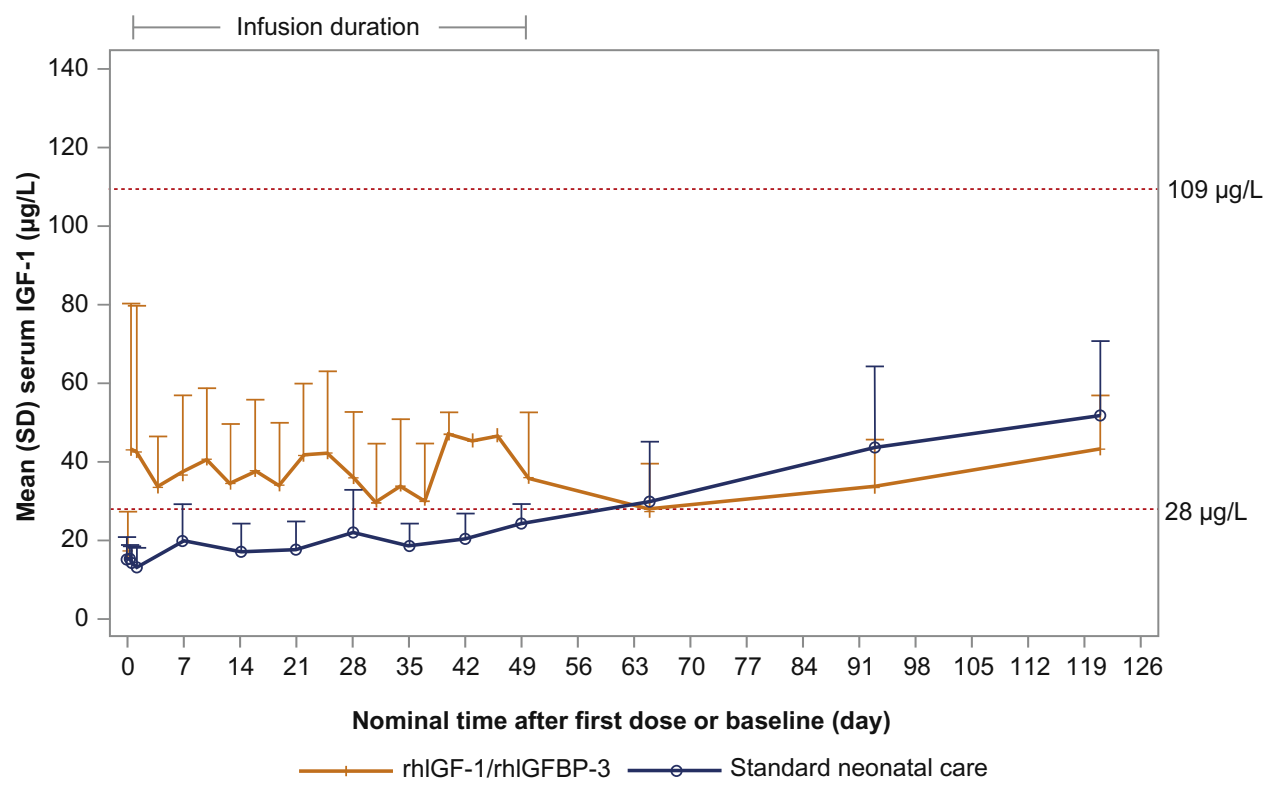

Figure 2. Mean (SD) serum IGF-1 concentrations over time in infants in the standard neonatal care and rhlGF-1/rhIGFBP-3 groups $(n=121)$. 


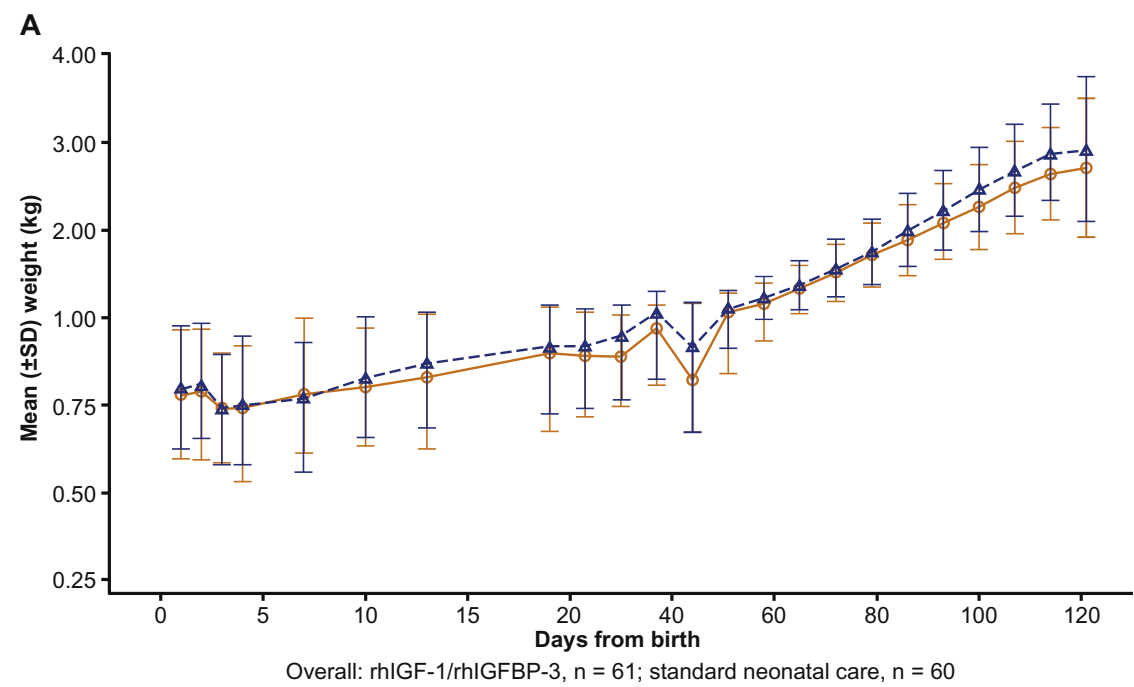

rhIGF-1/rhIGFBP-3 -.-- Standard neonatal care

B

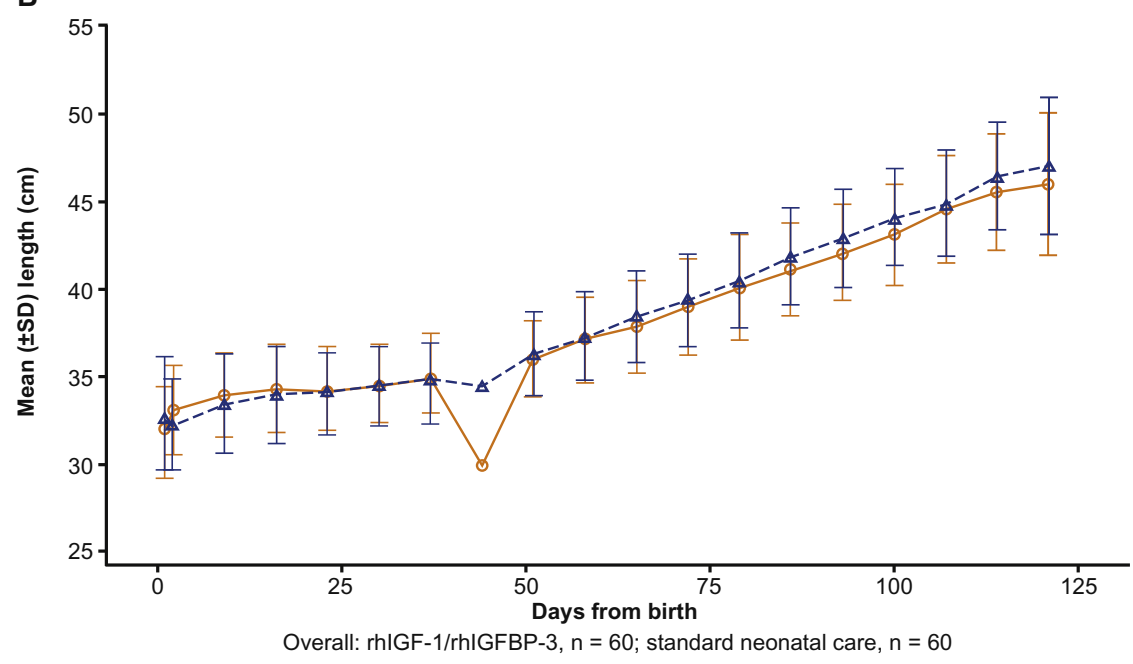
— rhlGF-1/rhlGFBP-3 ...- Standard neonatal care

C

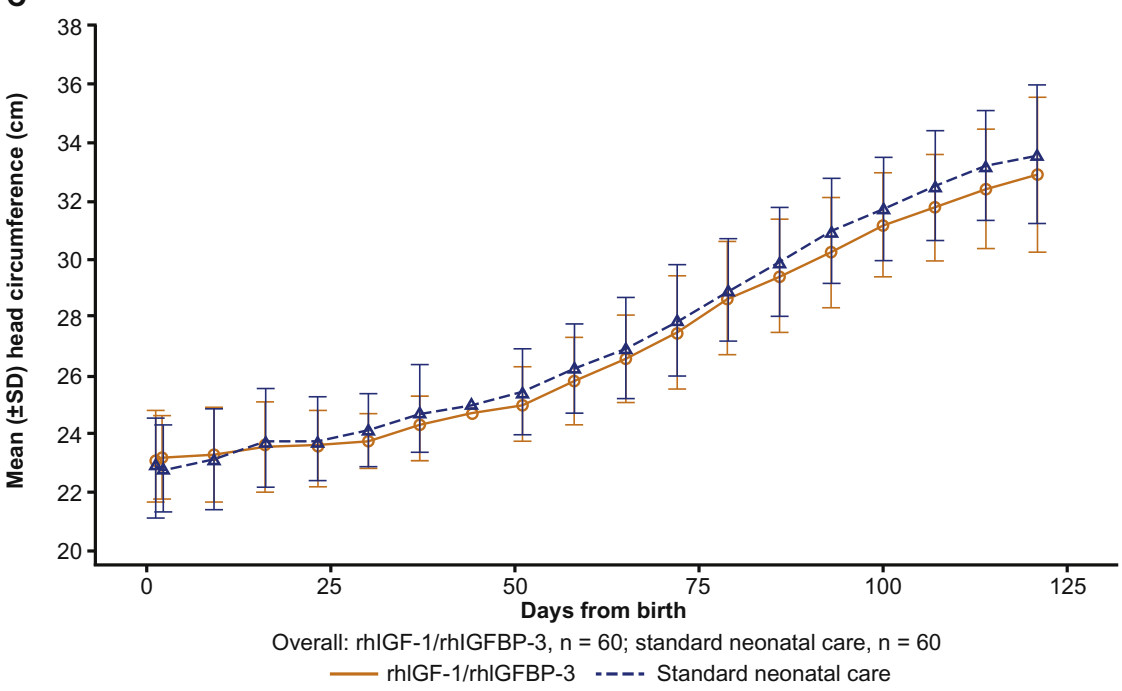

Figure 4. A, Average weight, B, length, and C, head circumference by treatment group (FAS). 
Table I. Verbatim terms reported in relation to common treatment-emergent AEs

AE/preferred term Verbatim terms

Patent ductus arteriosus

"Persistent ductus arteriosus," "patent ductus arteriosus that requires treatment," "patent ductus arteriosus that need treatment," "PDA," "large PDA," "large patent ductus arteriosus," "patent ductus arteriosus, moderately hemodynamically significant," "patent ductus arteriosus, minor hemodynamically significant," "PDA of $3.4 \mathrm{~mm}$ detected on first ECHO," "reopening of ductus arteriosus," "reopening of patent ductus arteriosus," "big patent ductus arteriosus," "small patent ductus arteriosus," "patent ductus arteriosus, hemodynamically significant," "patent ductus arteriosa without any clinical significance," "small PDA again," "homonymic significant patent ductus arteriosus," "patent ductus arteriosus (PDA)," "small closing patent ductus arteriosus," "patent ductus arteriosus $2.1 \mathrm{~mm}$," "patent ductus arteriosus with shunt pulsating flow pattern," "PDA prior to treatment," "patent ductus arteriosus from echocardiogram," "PDA observed on echocardiogram"

Anemia neonatal

"Anemia," "anemi," "anemia requiring transfusion," "anaemia," "anaemia of prematurity," "anemie," "tired, pale, listless due to anemia," "anaemia needed transfusion," "neonatal anaemia," "anemia of prematurity," "symptomatic anemia"

Neonatal respiratory

distress syndrome

Jaundice neonatal

Infantile apneic attack

Neonatal hypotension

"Respiratory distress syndrome," "RDS," "respiratory distress," "hyaline membrane disease," "infant respiratory distress syndrome," "respiratory distress/hyaline membrane disease"

"Jaundice," "jaundiced," "neonatal jaundice," "icterus," "jaundice requiring phototherapy,” "intermittent jaundice," "jaundice requiring treatment with phototherapy"

"Apnéas," "apneas," "apnéa," "apnea of prematurity," "apnea," "apnoea," "prematurity apnea," "apnoea crisis," "recurrent apnea," "recurrent apnoeas," "sudden and severe apnoea," "severe apnoea," "apnea episode," "apnea neonatal," "crisis of apnea"

"Hypotension," "low blood pressure," "hypotension (low blood pressure)," "systemic hypotension," "hypotensive (mean 21)," "intermittent hypotension," "hypotension (intermittent)," "hypotension, MAP 26 "

Hyperglycemia

"Hyperglycemia," "hyperglycaemia," "hyperglucemia," "hyperglicemia," "hyperglycemia (intermittent)," "hyperglycemia, blood glucose $26 \mathrm{mmol}$, insulin infusion commenced," "hyperglycemia, blood glucose $58 \mathrm{mmol}$ stat dose of insulin given," "hyperglycemia, blood glucose $45 \mathrm{mmol}$, insulin infusion concentration and dose increased"

Neonatal hyponatremia "Hyponatremia," "hyponatremi," "low natrium," "hyponatriemia," "hyponatraemia," "mild hyponatremia," "severe hyponatremia"

Sepsis neonatal

"Suspected sepsis, blood cultures negative," "suspected septicemia," "suspected sepsis," "sepsis," "sepsis (blood culture negative)," "sepsis due to Enterococcus faecalis, Staphilococcus aureus, and Staphilococcus haemoliticus," "late onset neonatal sepsis," "late onset sepsis," "suspected sepsis not confirmed (CRP negative)," "suspected sepsis (blood culture and tracheal aspiration were negative, the adverse event was not confirmed," "suspected sepsis (clinical instability, elevation of CRP but blood and CSF cultures were negative)," "clinical sepsis (desaturations, elevation of CRP but blood culture was negative)," "suspected sepsis (recurrent apneas but blood culture and CRP were negative)," "suspected sepsis (blood culture was negative) for clinical instability (desaturations)," "sepsis (etiology unknown, blood culture was negative)," "clinical sepsis (PCR, blood culture negative)," "possibility to sepsis, no bacteria found in blood culture," "presumed sepsis (blood cultures negative after 6 days)," "sepsis presumed, no growth on blood culture or nasopharyngeal aspirate," "presumed sepsis, blood cultures negative," "sepsis of unknown etiology," "suspected sepsis, not confirmed," "suspected sepsis, not confirmed, etiology unknown," "neonatal septicemia, staphylococcus capitis grown from blood culture," "possible sepsis, cultures negative," "suspected sepsis, rising infection parameters, no bacteria detected in cultures," "early onset sepsis," "presumed long line sepsis, cultures negative," suspected sepsis due to severe desaturations," "suspected sepsis (CSF and blood cultures were negative)," "clinical sepsis, etiology unknown (cultures remained negative)," "sepsis presumed in line with routine neonatal care of extreme premature baby, antibiotics stopped when sepsis ruled out," "sepsis suspected and therefore treated with antibiotics but blood cultures negative after 6 days," "sepsis suspected, blood cultures showed no growth after 6 days incubation," "sepsis (no growth from blood cultures after 6 days incubation, no other source of infection suspected)," "sepsis suspected, no sepsis confirmed," "suspected sepsis (in line with routine preterm neonatal care) (blood cultures negative after 6 days) antibiotics stopped," "presumed sepsis, no confirmed on blood cultures," "central line associated blood stream infection from PICC line," "clinical sepsis (bloody stool), and blood cultures negative"

Hypoglycemia neonatal "Hypoglycemia," "asymptomatic hypoglycaemia," "hypoglicemia," "hypoglycaemia," "hypoglycaemia as peripheral venous line delivering TPN was leaking," "hypoglycaemia (intermittent)," "hypoglycaemia, asymptomatic," "hypoglycaemia, 1.8," "hypoglycaemia, 1.6," "hypoglycaemia $(1.0 \mathrm{mmol} / \mathrm{l}$ at $6 \mathrm{pm})$ "

Metabolic acidosis

Staphylococcal sepsis

"Metabolic acidosis," "metabolic acidosis on blood gas"

"Septicemia: stafyloccus epidermidis," "staphylococcus epidermis in the blood," "coagulase negative staphylococci septicaemia," "sepsis (staphylococcus epidermidis)," "sepsis due to Bacillus Amyloliquefaciens and Staphilococcus Epidermidis," "sepsis due to staphylococcus epidermidis," "sepsis by staphylococcus aureus," "sepsis by oxacillin-resistant staphylococcus epidermis," "sepsis by Staphilococcus Aureus," "sepsis by Staphilococcus epidermidis probably originated by a skin lesion," "sepsis by staphylococcus warneri," "sepsis by MRSA," "sepsis from staphylococcus capitis," "sepsis from staphylococcus epidermidis," "coagulase-negative staphylococcal sepsis," "positive blood culture-staphylococcus epidermidis," "neonatal septicaemia, staphylococcus capitis grown from blood culture," "positive blood culture, staphylococcus epidermidis," "mild sepsis (Staphylococcus epidermidis)," "septicemia with coagulase negative staphylococci," "sepsis staph aureus and KNS," "staphylococcus sepsis," "sepsis due to staphylococcus epidermidis and staphylococcus warneri," "sepsis from staphylococcus capitis and epidermidis," "staphylococcus aureus bacteraemia sepsis," "sepsis by methicillin-resistant staphylococcus aureaus (MRSA)," "clinical sepsis by staphylococcus capitis oxacilline resistant," "sepsis staphylococcus haemolitycus," "sepsis from Staphylococcus Haemolitycus," "sepsis, blood cultures Staphyloccus capitis positive," "blood cultures showed mixed coagulase negative staphylococci," "sepsis, confirmed coag neg staph from blood cultures," "sepsis suspected, confirmed Staphylococcis capitis," "presumed sepsis, coagulase negative staph isolated from aerobic bottle after 1 day incubation," "sepsis, Staphylococcus pettenkoferi," "sepsis confirmed, Staphylococcus aureus and Staphylococcus epidermitis," "positive blood culture staphylococci epidermidis," "positive blood culture (gram positive cocci) Staphylococcus Epidermidis," "sepsis (positive blood culture Staphylococcus epidermidis noted)," "coagulase negative staphylococci septicaemia," "sepsis from staphylococcus epidermidis catheter associated"

Neonatal hypoxia "Increasing need of oxygen," "oxygen saturation decreased," "neonatal hypoxia," "repeated desaturations," "Iow saturation," "poor saturations and blood gases," "desaturations," "episodes of desaturations," "desaturation crisis," "frequent desaturations," "persistent need of oxygen in nCPAP with clinical instability (frequent desaturations)," "persistent need of oxygen in CPAP," "persistent need of oxygen," "prolonged need of oxygen," "hypoxia," "desaturation, need of increased oxygen," "increased need of oxygen," "oxygen saturation dips," "necessity of nCPAP at 28 days of life without oxygen," "oxygenation problems due to PIE," "respiratory step up (increase in the oxygen requirement)," "profound desaturation after a feed," "desaturation following a feed," "poor oxygen saturation," "oxygen desaturations," "desaturation associated with feeding," "low oxygen saturation (14\%)" 


\section{Table I. Continued}

\begin{tabular}{|c|c|}
\hline AE/preferred term & Verbatim terms \\
\hline $\begin{array}{l}\text { Neonatal respiratory } \\
\text { failure }\end{array}$ & $\begin{array}{l}\text { "Respiratory insufficiency," "respiratory crisis," "pulmonary insufficiency," "respiratory failure, ventilator dependent," "respiratory failure } \\
\text { unable to ventilate," "reintubation for impending respiratory failure," "respiratory instability," "respiratory failure unable to ventilate } \\
\text { infant," "respiratory failure" }\end{array}$ \\
\hline Hypokalemia & "Hypokalemia," "ipokaliemia," "hypokalaemia," "hypokalemi," "hypopotassemia" \\
\hline Bradycardia neonatal & "Bradycardia," "bradycardia episodes," "bradycardia (mean heart rate 56.3 bpm)," "bradycardia (heart rate <60 bpm)" \\
\hline $\begin{array}{l}\text { Hyperbilirubinemia } \\
\text { neonatal }\end{array}$ & "Hyperbilirubinemia," "hyperbilirubinemi," "hyperbillirubin," "hyperbillirubinemi," "hyperbilirubinaemia," "conjugated hyperbilirubaemia" \\
\hline Pulmonary hypertension & $\begin{array}{l}\text { "Persistent pulmonary hypertension," "pulmonary hypertension," "Persistent pulmonary hypertension of the newborn," "severe pulmonary } \\
\text { hypertension on study echocardiogram" }\end{array}$ \\
\hline
\end{tabular}

CPAP, continuous positive airway pressure; CRP, C-reactive protein; CSF, cerebrospinal fluid; MRSA, methicillin-resistant Staphylococcus aureus; $n C P A P$, nasal continuous positive airway pressure; PICC, peripherally inserted central catheter; PIE, pulmonary interstitial emphysema.

Table II. Anticipated distribution of the maximum severity of ROP (standard care and rhIGF-1/ rhIGFBP-3 groups) used for calculation of sample size ${ }^{\star}$

\begin{tabular}{lcccrrr}
\hline ROP & $\mathbf{0}$ & $\mathbf{1}$ & $\mathbf{2}$ & $\mathbf{3}$ & $>\mathbf{3}$ & Total \\
\hline Standard care (\%) & 26 & 15 & 24 & 18 & 17 & 100 \\
rhIGF-1/rhIGFBP-3 (\%) & 49 & 19 & 19 & 9 & 4 & 100
\end{tabular}

*Standard care group distribution based on registry data (Austeng. Arch Ophthalmol. 2009:127:1315-9); estimated treatment effect in the rhlGF-1/rhlGFBP-3 group based on the following assumptions: For each outcome of the maximum severity of ROP stage, it is assumed that $25 \%$ of the children will not benefit from the treatment, $25 \%$ will have their maximum severity of ROP stage reduced by 1 level (eg, from 2 to 1 ), and $50 \%$ will have their maximum severity of ROP stage reduced 2 levels (eg, from $3+$ to 2 ).

\begin{tabular}{|c|c|c|c|}
\hline \multirow[b]{2}{*}{ Variables } & \multicolumn{3}{|c|}{ rhIGF-1/rhIGFBP-3 } \\
\hline & $\begin{array}{c}\text { Overall } \\
\text { population } \\
(n=61)\end{array}$ & $\begin{array}{c}\text { Gestational } \\
\text { age }<26 \text { wk } \\
(n=35)\end{array}$ & $\begin{array}{l}\text { Gestational } \\
\text { age } \geq 26 \text { wk } \\
(n=26)\end{array}$ \\
\hline \multicolumn{4}{|c|}{$\begin{array}{l}\text { Total duration of } \\
\text { exposure, } \mathrm{d}^{*}\end{array}$} \\
\hline Mean & 23.8 & 27.4 & 18.9 \\
\hline Range & $0.1-45.3$ & $0.1-45.3$ & $1.8-26.7$ \\
\hline \multicolumn{4}{|c|}{$\begin{array}{l}\text { Ratio of duration of } \\
\text { exposure to expected } \\
\text { duration, } \mathrm{d}^{\dagger}\end{array}$} \\
\hline Mean & 0.86 & 0.85 & 0.88 \\
\hline Range & $0.0-1.0$ & $0.0-1.0$ & $0.6-1.0$ \\
\hline \multicolumn{4}{|c|}{ Overall dose, $\mu \mathrm{g} / \mathrm{kg}^{\ddagger}$} \\
\hline Mean & 5907.5 & 6849.8 & 4639.0 \\
\hline Range & $16.0-11,321.9$ & $16.0-11,321.9$ & $460.9-6664.1$ \\
\hline \multicolumn{4}{|c|}{$\begin{array}{l}\text { Average daily dose, } \\
\mu \mathrm{g} / \mathrm{kg} / 24 \text { hours }\end{array}$} \\
\hline Mean & 248.1 & 250.0 & 245.4 \\
\hline Range & $131.1-250.0$ & $250.0-250.0$ & $131.1-250.0$ \\
\hline \multicolumn{4}{|c|}{ Interruptions, no. } \\
\hline Mean & 4.0 & 5.7 & 1.6 \\
\hline Range & $0-83$ & $0-83$ & $0-9$ \\
\hline \multicolumn{4}{|c|}{ Length interruptions, $\mathrm{h}$} \\
\hline Mean & 7.5 & 10.2 & 3.9 \\
\hline Range & $0.0-52.6$ & $0.0-52.6$ & $0.0-30.8$ \\
\hline
\end{tabular}

*Total duration of exposure defined as (study medication end date - study medication start date) - duration of interruptions.

tRatio of duration of exposure to expected duration defined as total duration of exposure / (29 weeks $\times 7+6$ days) or the last day in the study-(birth weeks $\times 7+$ day) +1 .

$\ddagger$ Total dose $(\mu \mathrm{g} / \mathrm{kg})$ defined as the sum of weight-adjusted doses during the exposure.

$\S$ Average daily dose $(\mu \mathrm{g} / \mathrm{kg} / 24$ hours) defined as overall dose/total duration of exposure across the entire study.
Table VI. Maximum severity of ROP stage across all examinations by a central pediatric ophthalmologist by gestational age strata (FAS and ES)

\begin{tabular}{|c|c|c|c|}
\hline \multirow[b]{2}{*}{ Gestational age groups } & \multirow{2}{*}{$\begin{array}{l}\text { Standard } \\
\text { care } \\
(n=32)\end{array}$} & \multicolumn{2}{|c|}{ rhIGF-1/rhIGFBP-3 } \\
\hline & & $\begin{array}{c}\text { FAS } \\
(n=35)\end{array}$ & $\begin{array}{c}\text { ES } \\
(n=10)\end{array}$ \\
\hline \multicolumn{4}{|l|}{$<26$ wk } \\
\hline $\begin{array}{l}\text { Infants with ROP examination, no. } \\
\text { Infants with maximum severity } \\
\text { of ROP of stage, no. (\%) }\end{array}$ & 26 & 25 & 9 \\
\hline 0 & $8(30.8)$ & $5(20.0)$ & $2(22.2)$ \\
\hline 1 & $2(7.7)$ & $2(8.0)$ & 0 \\
\hline 2 & $9(34.6)$ & $7(28.0)$ & $4(44.4)$ \\
\hline 3 & $2(7.7)$ & $5(20.0)$ & $1(11.1)$ \\
\hline $3+$ & $5(19.2)$ & $6(24.0)$ & $2(22.2)$ \\
\hline 4 & 0 & 0 & 0 \\
\hline 5 & 0 & 0 & 0 \\
\hline$\geq 3$ & $7(26.9)$ & $11(44.0)$ & $3(33.3)$ \\
\hline Missing & 6 & 10 & 1 \\
\hline$\geq 26$ wk & $\mathrm{n}=28$ & $\mathrm{n}=26$ & $\mathrm{n}=14$ \\
\hline $\begin{array}{l}\text { Infants with ROP examination, no. } \\
\text { Infants with maximum severity } \\
\text { of ROP of stage, no. (\%) }\end{array}$ & 24 & 22 & 13 \\
\hline 0 & $16(66.7)$ & $9(40.9)$ & $6(46.2)$ \\
\hline 1 & $2(8.3)$ & $2(9.1)$ & $2(15.4)$ \\
\hline 2 & $4(16.7)$ & $10(45.5)$ & $4(30.8)$ \\
\hline 3 & $1(4.2)$ & $1(4.5)$ & $1(7.7)$ \\
\hline $3+$ & $1(4.2)$ & 0 & 0 \\
\hline 4 & 0 & 0 & 0 \\
\hline 5 & 0 & 0 & 0 \\
\hline$\geq 3$ & $2(8.3)$ & $1(4.5)$ & $1(7.7)$ \\
\hline Missing & 4 & 4 & 1 \\
\hline
\end{tabular}




\begin{tabular}{|c|c|c|c|}
\hline \multirow[b]{2}{*}{ Gestational age groups } & \multirow{2}{*}{$\begin{array}{c}\text { Standard } \\
\text { care } \\
(n=32)\end{array}$} & \multicolumn{2}{|c|}{ rhIGF-1/ rhIGFBP-3 } \\
\hline & & FAS $(n=35)$ & $E S(n=10)$ \\
\hline \multicolumn{4}{|l|}{$<26 \mathrm{wk}$} \\
\hline $\begin{array}{l}\text { Infants with BPD assessment, no. } \\
\text { Severity of BPD, no. (\%) }\end{array}$ & 25 & 25 & 8 \\
\hline No BPD & $1(4.0)$ & $1(4.0)$ & 0 \\
\hline Mild & $5(20.0)$ & $10(40.0)$ & $4(50.0)$ \\
\hline Moderate & $4(16.0)$ & 7 (28.0) & $3(37.5)$ \\
\hline Severe & $14(56.0)$ & $6(24.0)$ & $1(12.5)$ \\
\hline Unable to determine & $1(4.0)$ & $1(4.0)$ & 0 \\
\hline \multicolumn{4}{|l|}{$\geq 26$ wk } \\
\hline $\mathrm{n}$ & 28 & 26 & 14 \\
\hline $\begin{array}{l}\text { Infants with BPD assessment, no. } \\
\text { Severity of BPD, no. (\%) }\end{array}$ & 24 & 22 & 13 \\
\hline No BPD & $3(12.5)$ & $3(13.6)$ & $2(15.4)$ \\
\hline Mild & $11(45.8)$ & $13(59.1)$ & $9(69.2)$ \\
\hline Moderate & $1(4.2)$ & $2(9.1)$ & $2(15.4)$ \\
\hline Severe & $8(33.3)$ & $4(18.2)$ & 0 \\
\hline Unable to determine & $1(4.2)$ & 0 & 0 \\
\hline
\end{tabular}

Table VIII. Percentage of infants with IVH by grade and gestational age strata (FAS and ES)

\begin{tabular}{|cccc|} 
& \multirow{2}{*}{$\begin{array}{c}\text { Standard } \\
\text { care }\end{array}$} & \multicolumn{2}{c}{ rhIGF-1/ rhIGFBP-3 } \\
\cline { 4 - 4 } Gestational age groups & $(\mathbf{n}=\mathbf{3 2})$ & FAS $(\mathbf{n}=\mathbf{3 5})$ & ES $\mathbf{( n = 1 0 )}$ \\
\hline$<26$ wk & & & \\
IVH grade, no. (\%) & & & \\
$0-1$ & $20(62.5)$ & $27(77.1)$ & $9(90.0)$ \\
2 & $3(9.4)$ & $3(8.6)$ & $1(10.0)$ \\
3 & $6(18.8)$ & $3(8.6)$ & 0 \\
4 & $3(9.4)$ & $2(5.7)$ & 0 \\
$\geq 26$ wk & & & \\
n & 28 & 26 & 14 \\
IVH grade, no. (\%) & & & \\
$0-1$ & $22(78.6)$ & $22(84.6)$ & $11(78.6)$ \\
2 & $1(3.6)$ & $1(3.8)$ & $1(7.1)$ \\
3 & $3(10.7)$ & $3(11.5)$ & $2(14.3)$ \\
4 & $2(7.1)$ & 0 & 0 \\
\hline
\end{tabular}

\begin{tabular}{|c|c|c|c|c|}
\hline \multirow[b]{2}{*}{$\begin{array}{l}\text { Infants with BPD } \\
\text { assessment or } \\
\text { death, no.* }\end{array}$} & \multicolumn{2}{|c|}{$\begin{array}{l}\text { Standard care } \\
(n=60)\end{array}$} & \multicolumn{2}{|c|}{$\begin{array}{l}\text { rhIGF-1/rhIGFBP-3 FAS } \\
(n=61)\end{array}$} \\
\hline & $56^{\dagger}$ & & $59^{\dagger}$ & \\
\hline Severity of BPD & №. (\%) & $95 \% \mathrm{Cl}$ & №. (\%) & $95 \% \mathrm{Cl}$ \\
\hline No BPD/mild & $20(35.7)$ & $(24.5-48.8)$ & $27(45.8)$ & $(33.7-58.3)$ \\
\hline Moderate & $5(8.9)$ & (3.9-19.3) & $9(15.3)$ & $(8.2-26.5)$ \\
\hline Severe/death & $29(51.8)$ & $(39.0-64.3)$ & $22(37.3)$ & $(26.1-50.1)$ \\
\hline Unable to determine & $2(3.6)$ & $(1.0-12.1)$ & $1(1.7)$ & $(0.3-9.0)$ \\
\hline
\end{tabular}

*There were 19 all-cause deaths that occurred during the study, 12 deaths in the rhlGF-1/ rhIGFBP-3 group and 7 deaths in the standard care group.

†Four infants in the standard care group and 2 infants in the rhIGF-1/rhlGFBP-3 FAS were withdrawn from the study before being assessed for BPD.

Table X. Most common treatment-emergent AEs (preferred terms, occurring in $\geq 20 \%$ in any treatment group)

\begin{tabular}{|c|c|c|c|c|}
\hline \multirow[b]{2}{*}{ AEs } & \multicolumn{2}{|c|}{$\begin{array}{l}\text { Standard care } \\
(n=60)\end{array}$} & \multicolumn{2}{|c|}{$\begin{array}{l}\text { rhIGF-1/rhIGFBP-3 } \\
(n=61)\end{array}$} \\
\hline & $\begin{array}{l}\text { Infants, } \\
\text { no. (\%) }\end{array}$ & $\begin{array}{c}\text { Events, } \\
\text { no. }\end{array}$ & $\begin{array}{l}\text { Infants, } \\
\text { no. (\%) }\end{array}$ & $\begin{array}{c}\text { Events, } \\
\text { no. }\end{array}$ \\
\hline Patent ductus arteriosus & $51(85.0)$ & 71 & $55(90.2)$ & 80 \\
\hline Anemia neonatal & 44 (73.3) & 157 & $46(75.4)$ & 210 \\
\hline $\begin{array}{l}\text { Neonatal respiratory } \\
\text { distress syndrome }\end{array}$ & $34(56.7)$ & 49 & $29(47.5)$ & 34 \\
\hline Jaundice neonatal & $30(50.0)$ & 38 & $28(45.9)$ & 34 \\
\hline Infantile apneic attack & $17(28.3)$ & 35 & 27 (44.3) & 48 \\
\hline Neonatal hypotension & $18(30.0)$ & 30 & $25(41.0)$ & 35 \\
\hline Hyperglycemia & $29(48.3)$ & 58 & $24(39.3)$ & 41 \\
\hline Neonatal hyponatremia & $22(36.7)$ & 39 & $23(37.7)$ & 43 \\
\hline Sepsis neonatal ${ }^{\star}$ & $15(25.0)$ & 30 & $23(37.7)$ & 41 \\
\hline Hypoglycemia neonatal & 19 (31.7) & 28 & $18(29.5)$ & 22 \\
\hline Metabolic acidosis & $22(36.7)$ & 46 & $17(27.9)$ & 48 \\
\hline Staphylococcal sepsis & $19(31.7)$ & 25 & $16(26.2)$ & 24 \\
\hline Neonatal hypoxia ${ }^{\dagger}$ & $13(21.7)$ & 22 & $14(23.0)$ & 17 \\
\hline Neonatal respiratory failure $e^{\ddagger}$ & $14(23.3)$ & 18 & $14(23.0)$ & 22 \\
\hline Hypokalemia & $11(18.3)$ & 18 & $14(23.0)$ & 24 \\
\hline Bradycardia neonatal $^{\S}$ & $5(8.3)$ & 6 & $13(21.3)$ & 19 \\
\hline Hyperbilirubinemia neonatal & $14(23.3)$ & 18 & $12(19.7)$ & 14 \\
\hline Pulmonary hypertension & $12(20.0)$ & 14 & 8 (13.1) & 8 \\
\hline
\end{tabular}

Events of ROP, BPD, and IVH also were reported as treatment-emergent AEs in some but not all cases; however, they are not included in the table because these are efficacy outcomes. *Verbatim terms include suspected/presumed sepsis and some microbiologically confirmed cases of sepsis, but do not encompass all cases of sepsis (nonspecific term). See Table I for a list of reported verbatim terms under the preferred term "sepsis neonatal."

tSee Table I for verbatim terms reported under the preferred term "neonatal hypoxia."

¥See Table I for verbatim terms reported under the preferred term "neonatal respiratory failure." \$Frequency in rhlGF-1/rhlGFBP-3 group at least twice that of the standard care group. 